\title{
Complications in laparoscopic and robotic-assisted surgery: definitions, classifications, incidence and risk factors - an up-to-date review
}

\author{
Rafat Watrowski ${ }^{1}$, Stoyan Kostov ${ }^{2}$, Ibrahim Alkatout ${ }^{3}$ \\ ${ }^{1}$ St. Josefskrankenhaus, Teaching Hospital of the University of Freiburg, Freiburg, Germany \\ 2Department of Gynecology, Medical University Varna, Varna, Bulgaria \\ ${ }^{3}$ Department of Gynecology and Obstetrics, Kiel School of Gynecological Endoscopy, University Hospitals Schleswig-Holstein, Kiel, \\ Germany
}

Videosurgery Miniinv 2021; 16 (3): 501-525 DOI: https://doi.org/10.5114/wiitm.2021.108800

\begin{abstract}
Almost all gynecological and general-surgical operations are-or can be-performed laparoscopically. In comparison to an abdominal approach, the minimally invasive access offers several advantages; however, laparoscopy (both conventional and robotic-assisted) can be associated with a number of approach-specific complications. Although the majority of them are related to the laparoscopic entry, adverse events may also occur due to the presence of pneumoperitoneum or the use of laparoscopic instruments. Unfortunately, a high proportion of complications (especially affecting the bowel and ureter) remain unrecognized during surgery. This narrative review provides comprehensive up-to-date information about definitions, classifications, risk factors and incidence of surgical complications in conventional and robotic-assisted laparoscopy, with a special focus on gynecology. The topic is discussed from various perspectives, e.g. in the context of stage of surgery, injured organs, involved instruments, and in relation to malpractice claims.
\end{abstract}

Key words: complications, risk factors, incidence, classification, gynecological laparoscopy, robotic-assisted surgery.

\section{Introduction}

Since its beginnings in the 1970s, laparoscopy has gradually become the standard surgical approach to the abdominal cavity in all surgical specialties including gynecology [1]. The benefits of modern laparoscopy are: decreased blood loss, less postoperative pain, fewer wound complications, reduced risk of adhesion formation, shorter hospital stay, faster return to daily activities, excellent cosmetic results [2-5], and lower treatment costs in comparison to open abdominal procedures [3-5]. The implementation of robotic-assisted laparoscopic surgery (RALS) - fol- lowing the USA Food and Drug Administration approval for the first DaVinci system in 2005 - allowed for further minimizing intraoperative blood loss and acceleration of patient recovery [6-8]. Despite the undoubted advantages, the minimally invasive approach does not rule out the possibility of adverse events [9-15]. Depending on definitions and classifications used, $0.2-18 \%$ of conventional and 3-15\% of robotic-assisted gynecological laparoscopies are associated with (either intra- or postoperative) adverse events (AEs). Fatalities resulting from a laparoscopic approach occur in $0.02 \%$ (0.01-0.03\%) of cases and are most often related to injuries of large 
retroperitoneal vessels, and - less frequently - to bowel injuries [14-27]. Compared to open surgery, laparoscopy for benign indications is associated with similar rates of severe complications (1.4\%) but a significantly lower incidence of "minor" complications (15.2\% vs. $4.3-8.9 \%)$ [10, 11, 15].

In turn, in comparison to conventional laparoscopic surgery (CLS), RALS is associated with further benefits, such as decreased intraoperative bleeding, reduced need for transfusions, lower level of postoperative pain, shorter hospital stay and faster convalescence, while showing similar rates of intraoperative, and roughly comparable rates of postoperative complications [6, 7, 12, 13, 28].

Although complication rates increase with the complexity of the procedure, a considerable proportion of severe incidents still occur during diagnostic or minor procedures (e.g. sterilization). This is because half of the complications occur during laparoscopic entry $[9,10,15-17,21,25-27]$. For some exclusively laparoscopy-related incidents, e.g. postlaparoscopic shoulder pain, subcutaneous emphysema or morcellation of occult malignancy, minimally invasive access is a prerequisite.

Unique limitations of the conventional laparoscopic approach are:

- (Usually) blind entry into the peritoneal cavity,

- Restricted vision (fixed angle of view; limitations resulting from smoke, fog or bleeding; dependence of camera assistant),

- Often two-dimensional field of view,

- Fixed trocar positions with limited degrees of freedom,

- Limited tactile feedback,

- Effects of intra-abdominal pressure (overstretching of nerves, impaired ventilation),

- Physical and chemical effects of the insufflation gas $\left(\mathrm{CO}_{2}\right)$,

- Necessity of specimen fragmentation (morcellation) prior to evacuation.

The aforementioned limitations can be attenuated, but not eliminated, by technical improvements (3D optical systems, 4K display resolution, integrated smoke evacuation systems).

The RALS differs from CLS in terms of:

- Improved visibility due to angulated optical instruments with 3D optics,

- Variable use of optics in all four trocars,

- Integrated fluorescence imaging near-infrared technology (FireFly mode),
- Motion dampening sensors (tremor filtration),

- Wristed instrumentation with up to $7^{\circ}$ of freedom,

- Larger trocars compared to CLS (Da Vinci Si System),

- Absence of tactile feedback,

- Longer setup of the robotic equipment,

- Longer total operating time (conflicting data),

- Higher costs,

- Longer learning curve which has to be traversed even by experienced laparoscopists [6-8, 28].

\section{Aim}

This review aims to provide essential knowledge about definitions, classifications, incidence rates and risk factors of procedure-related complications of CLS and RALS, with special focus on gynecology. Complication management and non-approach-specific AEs (e.g. anaesthesia-related problems or hospital-acquired infections) are not topics of the present work.

\section{Material and methods}

We chose the form of a narrative review as the most appropriate for discussing a broad range of questions from different perspectives, e.g. according to the time of occurrence, affected organs, and involved instruments. We adhered to the quality standards for narrative reviews, as defined by experts [29] and quantified by "SANRA - a scale for the quality assessment of narrative review articles" [30]. The relevant publications were identified after systematic query of the following sources: PubMed, Google Scholar, Cochrane Library, SciELO, and publishers' databases (Elsevier/ScienceDirect, Wiley, Taylor \& Francis, Springer, Sage, Mary Ann Liebert, Wolters Klouwer/Lippincott, Hindawi, Termedia, and Via Medica), complemented by cross-check of the reference lists. We used a combination of the search terms "complication", "adverse event", "injury", "intraoperative" and "iatrogenic" with terms relevant to the topic of each paragraph (e.g. "vessel", "vascular", "aorta"), with and without restriction to "gynecology/gynecologic". With singular exceptions ("classical" publications in the field and unique case reports), only papers published in the $21^{\text {st }}$ century were included. The final selection of references was made after full-text reading. We examined all types of publications (original research, systematic reviews, meta-analyses, narrative reviews, and case 
reports). When multiple studies reported similar results, we selected those that were the most up to date and represented the highest methodological quality. Publications related to non-procedure-specific complications were excluded. No language restrictions were applied.

\section{Definitions of surgical adverse events}

The U.S. National Institutes of Health (NIH) and the National Cancer Institute $(\mathrm{NCl})$ recommend the definition of an adverse event (AE) as "any unfavorable and unintended sign (including an abnormal laboratory finding), symptom, or disease temporally associated with the use of a medical treatment or procedure that may or may not be considered related to the medical treatment or procedure" [31]. The NIC provides "Common Terminology Criteria for Adverse Events (CTCAE)" reporting, a freely accessible and regularly updated catalogue (in the current version 145 pages), including definitions and grading for each type of AEs [31]. The $\mathrm{NCl}$ five-level grading of AEs is presented in Table I. The newest version of the CTCAE (6.0) is announced for the fall of 2022. The CTCAE is recommended for reporting of AEs by health services and used in clinical trials, e.g. the LACC (Laparoscopic Approach to Carcinoma of the Cervix) trial [32].

Some authors interpret the meaning of "complications" more broadly than that of AEs, that is (besides "events") as any kind of undesirable treatment course, e.g. prolonged hospitalization resulting from healthcare system or institutional policies [33]. However, commonly the terms "AEs" and "complications" are used interchangeably [32, 34-36]. Clavien et al. [35, 36] distinguished between three types of negative postoperative outcomes: "complications", "sequelae", and "failure to cure". A complication was defined as any deviation from the normal postoperative course, inclusive "asymptomatic complications such as arrhythmia or atelectasis". A sequela was proposed for any "after-effect" of surgery that was inherent to the procedure (e.g., inability to walk after amputation of the leg). Failure to cure would occur, when - despite an uncomplicated surgical course the intended result of surgery, e.g., complete oncological cytoreduction, could not be achieved. In fact, "sequelae" and "failure to cure" should be assessed separately from complications $[35,36]$. For this purpose, Sokol and Wilson [37] established the following, widely accepted definition of surgical complication - which we also use in the present review (synonymously to AE): "any undesirable, unintended, and direct result of an operation affecting the patient, which would not have occurred had the operation gone as well as could reasonably be hoped" [37]. They argued that, although in high-risk procedures complications can be "expected", two conditions define a surgical complication: it is always unintentional and occurs although an uncomplicated surgical course was realistic [37].

\section{Classifications of surgical complications}

Surgical complications can be classified according to:

a) their severity: from "mild/minor" through "severe/major" to "lethal";

b) time period: preoperative, intraoperative, early postoperative, late postoperative;

Table I. Common Terminology Criteria for Adverse Events (CTCAE) v5.0 - guideline for severity description of adverse events

\begin{tabular}{|c|c|c|}
\hline \multicolumn{2}{|c|}{ Grade } & Description \\
\hline 1 & Mild & $\begin{array}{c}\text { Asymptomatic or mild symptoms; clinical or diagnostic observations only; intervention } \\
\text { not indicated }\end{array}$ \\
\hline 2 & Moderate & $\begin{array}{l}\text { Minimal, local or noninvasive intervention indicated; limiting age-appropriate instrumen- } \\
\qquad \operatorname{tal} \mathrm{ADL}^{*}\end{array}$ \\
\hline 3 & Severe & $\begin{array}{l}\text { Severe or medically significant but not immediately life-threatening; hospitalization or } \\
\text { prolongation of hospitalization indicated; disabling; limiting self care } A D L^{* *}\end{array}$ \\
\hline 4 & Life-threatening & Life-threatening consequences; urgent intervention indicated \\
\hline 5 & Death & Death related to an adverse event \\
\hline
\end{tabular}

$A D L$ - Activities of Daily Living. *Instrumental ADL refer to preparing meals, shopping for groceries or clothes, using the telephone, managing money, etc.; ${ }^{*}$ Self care ADL refer to bathing, dressing and undressing, feeding oneself, using the toilet, taking medications, and not bedridden. 
c) stage of surgery: laparoscopic entry, main part of surgery including dissection of anatomical structures, trocar removal and leaving the abdominal cavity;

d) injured organs, e.g. vascular, intestinal, urological, or neurological injuries;

e) causality: instrument-related, pneumoperitoneum-related, surgeon-related etc.;

f) specificity: "surgical and approach-specific", e.g. morcellator related complications or pneumoperitoneum-related incidents; "surgical and approach-independent", e.g. organ injury due to severe adhesions; and "non-surgical", e.g. anesthesiologic complications or hospital infections.

Unfortunately, several important reports did not strictly differentiate between intra- and postoperative complications [9-11, 15]. Additionally, the surgical literature contains a variety of occasional and hybrid terminologies, making even important results hard to generalize. For instance, in their seminal work Wechter et al. [12] propose an eclectic distinction between "benign simple", "benign complex", "urogynecological" and "oncological" RALS procedures, wherein "adhesiolysis" is classified concurrently as a "simple complex" or "oncological" procedure, and "urogynecological" procedures are handled separately from "benign complex".

\section{Classifications according to severity, complexity and time of occurrence}

The severity is often the first and main criterion used for classification of surgical AEs. Unfortunately, the reporting of AEs in surgical studies is commonly unsatisfactory. For instance, intra- and postoperative complications are defined in only $13 \%$ and $50 \%$ of trials, respectively, and classification systems are used in $9 \%$ for intraoperative and in 54\% for postoperative AEs, respectively [34]. A systematic review of 179 trials from the area of oesophago-gastric and gynecologic-oncological surgery revealed that definitions of AEs (e.g. according to the CTCAE) and their grading (e.g. the Clavien-Dindo classification) were provided in only $27.3 \%$ and $16.8 \%$ of studies, respectively [38]. Classification grading systems allow for reliable and comparable reporting of AEs. They rely on additional interventions, necessary medications, affected organs, and duration of a patient's impairment or eventually life-long disability resulting from a complication.

\section{Intraoperative complications}

A practical classification of intraoperative complications has been proposed by Satava [39] and improved by Kazaryan et al. [40] (Table II). This threegrade classification of intraoperative incidents attempts to combine general (e.g. necessity of changing the operative approach) with subjective or adjustable (e.g. "normal" or expected blood loss) criteria [40]. The latter can, however, be a point of criticism because of possibly imprecise and incomparable results (e.g. the proposed use of "values typical for own institution").

A sufficient combination of universality and practicability has been obtained by the European Association of Urology (EAU) grading of intraoperative incidents (Table III) [41]. The EAU classification of intraoperative incidents could be a useful aid, being applicable for all surgical specialties.

\section{Postoperative complications}

In regard to the postoperative period, two classification systems have gained broad recognition: the Accordion Severity Classification of Postoperative

Table II. Satava-Kazaryan classification of unfavorable intraoperative incidents

\begin{tabular}{|lr|}
\hline Grade & Definition of intraoperative incidents \\
\hline 1 & $\begin{array}{r}\text { Incidents managed without change of operative approach and without further consequences for the patient. } \\
\text { This includes minor injury of adherent or adjacent organs and minimal change of intraoperative tactics and } \\
\text { cases with blood loss over normal range* }\end{array}$ \\
\hline $2 \quad \begin{array}{c}\text { Incidents with further consequences for the patient. This includes cases requiring limited resection of intraop- } \\
\text { eratively injured organs or cases with blood loss which is appreciably over the normal range*. For laparoscopic/ } \\
\text { thoracoscopic/endoscopic surgery it includes intraoperative incidents requiring conversion }\end{array}$ \\
\hline Incident leading to significant consequences for patient \\
\hline $\begin{array}{c}\text { * "A normal range of blood loss for each particular procedure is subjective in a certain degree, but one can } \\
\text { quantify it in regard to different procedures based both on contemporary scientific literature and values typical } \\
\text { for own institution." [40] }\end{array}$ \\
\hline
\end{tabular}


Table III. European Association of Urology intraoperative adverse incidents grading [41]

\begin{tabular}{|c|c|}
\hline Grade & Description \\
\hline 0 & $\begin{array}{l}\text { Event requiring no intervention or change in operative approach, no deviation from planned intraoperative } \\
\qquad \text { steps, no consequence for the patient }\end{array}$ \\
\hline 1 & $\begin{array}{l}\text { Event requiring additional/alternative procedure in planned intraoperative steps, not life-threatening or involv- } \\
\text { ing part or full organ removal. The event was addressed in a controlled manner with no long-term side effects }\end{array}$ \\
\hline 2 & $\begin{array}{l}\text { Event requiring major additional/alternative procedure in operative approach but NOT immediately life-threat- } \\
\text { ening. The event was addressed in a controlled manner, but may have short- or long-term side effects }\end{array}$ \\
\hline 3 & $\begin{array}{c}\text { Event requiring major additional/alternative procedure in addition to planned intraoperative steps and incident } \\
\text { becoming immediately life-threatening but NOT requiring part or full organ removal; may have short- or long- } \\
\text { term side effects }\end{array}$ \\
\hline 4 & $\begin{array}{l}\text { Event requiring major additional/alternative procedure in addition to planned intraoperative steps becoming } \\
\text { immediately life-threatening and with short- or long-term consequences to patient: } \\
\text { A. Requiring part or full organ removal } \\
\text { B. Unable to complete planned procedure as planned due to a technical issue or surgical event and/or required } \\
\text { unplanned stoma (change in body image, e.g. stoma, major skin flap) }\end{array}$ \\
\hline 5 & $\begin{array}{l}\text { A. Wrong site or side for ablative surgery or removal of an organ or wrong patient or no consent } \\
\text { B. Intraoperative death }\end{array}$ \\
\hline
\end{tabular}

Complications [42] and the Clavien-Dindo Classification of Surgical Complications (Table IV) [35, 36]. The first of them outlines four severity grades - "mild", "moderate", severe" and "death" - whereas the latter uses a 5-point Likert scale. The Clavien-Dindo classification was initially devised for general surgery and transplantology [43] but is suitable for CLS and RALS [12, 13, 28, 44].

\section{Surgical complexity}

Finally, it is crucial to distinguish between "complicated" and "complex" procedures, since thousands of patients undergo "complex" surgery without AEs, and, on the other hand, "major" complications also occur during "minor" procedures [15]. Nevertheless, the complication rates statistically decrease with the surgeon's experience and increase with the complexity of the surgical procedure [10, 12, 13, 15]. In terms of defining sustainable training and certification goals, international (e.g. the European Society for Gynaecological Endoscopy (ESGE) [45]) and national (e.g. the German Society for Gynaecological Endoscopy (AGE) [46]) laparoscopic boards proposed their own classifications of surgical complexity, based on the four-level grading proposed (more than two decades ago) by Chapron et al. [15]. Table $\mathrm{V}$ provides examples of these three classification systems of surgical laparoscopical complexity.

Of note, the difficulty level of myomectomy or hysterectomy is rated differently by these popular grading systems. The category "ectopic pregnancy" is not listed in the ESGE classification. While the "treatment of pelvic floor disorders" is assigned to the highest difficulty level by the ESGE [45], urogynecological procedures are divided into "cervical- and colposacrocopoplexy" (level 3) and "complex pelvic reconstruction" (level 4) by the AGE [46]. Procedures for "endometrial and cervical cancer" - despite their different extent and type - were confusingly placed together by Chapron et al. [15].

\section{Incidence of laparoscopic complications}

The awareness of frequency ranges of typical laparoscopic complications is indispensable for the consideration of treatment options and informed consent prior to surgery. However, the incidence of reported perioperative AEs varies depending on definitions, proportion of minor to major procedures in the analyzed sample, inter-institutional variability, or differences between individual surgeons. These facts explain the broad range of complication rates which can be found in the literature: the overall incidence of $0.2 \%$ to $18 \%$ for CLS, and $3.2 \%$ to $14.6 \%$ for RALS; "major" complications observed after $0.6 \%$ to $14.6 \%$ of CLS, and $4.1 \%$ to $6.4 \%$ of RALS, and intraoperative AEs noted in 2.7 to $7.5 \%$ of CLS and in $1.6 \%$ to $3.5 \%$ of RALS [12, 13, 44].

Chapron et al. describe undesirable surgical events in $0.08 \%, 0.4 \%$ and $1.7 \%$ of "minor", "major" and "advanced" gynecologic laparoscopies, respectively 
Table IV. Accordion severity classification of postoperative complications and Clavien-Dindo classification of postoperative surgical complications

\begin{tabular}{|c|c|c|c|}
\hline Severity & $\begin{array}{l}\text { Accordion Severity Classification } \\
\text { of Postoperative Complications } \\
\text { (Contracted Classification) [42] }\end{array}$ & $\begin{array}{l}\text { Clavien-Dindo Classification of Surgical } \\
\text { Complications }[35,36]\end{array}$ & Grade \\
\hline $\begin{array}{l}\text { 1. Mild compli- } \\
\text { cation }\end{array}$ & $\begin{array}{l}\text { Requires only minor invasive proce- } \\
\text { dures that can be done at the bedside } \\
\text { such as insertion of intravenous lines, } \\
\text { urinary catheters, and nasogastric } \\
\text { tubes, and drainage of wound infec- } \\
\text { tions. Physiotherapy and the following } \\
\text { drugs are allowed: antiemetics, anti- } \\
\text { pyretics, analgesics, diuretics, electro- } \\
\text { lytes, and physiotherapy }\end{array}$ & $\begin{array}{l}\text { Any deviation from the normal postoperative course } \\
\text { without the need for pharmacological treatment or } \\
\text { surgical, endoscopic, and radiological interventions. } \\
\text { Allowed therapeutic regimens are: antiemetic, } \\
\text { antipyretic, analgesic, or diuretic drugs, electrolytes, } \\
\text { and physiotherapy. This grade also includes wound } \\
\text { infections opened at the bedside }\end{array}$ & Grade 1 \\
\hline $\begin{array}{l}\text { 2. Moderate } \\
\text { complication }\end{array}$ & $\begin{array}{l}\text { Requires pharmacologic treatment } \\
\text { with drugs other than those allowed } \\
\text { for minor complications, for instance } \\
\text { antibiotics. Blood transfusions and total } \\
\text { parenteral nutrition are also included }\end{array}$ & $\begin{array}{c}\text { Requiring pharmacological treatment with drugs } \\
\text { other than those allowed for grade } 1 \text { complications. } \\
\text { Blood transfusions and total parenteral nutrition are } \\
\text { also included }\end{array}$ & Grade 2 \\
\hline \multirow[t]{2}{*}{$\begin{array}{l}\text { 3. Severe com- } \\
\text { plication }\end{array}$} & \multirow[t]{2}{*}{$\begin{array}{c}\text { All complications requiring endoscopic } \\
\text { or interventional radiologic procedures } \\
\text { or re-operation as well as complications } \\
\text { resulting in failure of one or more organ } \\
\text { systems. }\end{array}$} & $\begin{array}{l}\text { Requiring surgical, endoscopic or radiological } \\
\text { intervention: } \\
\text { Grade 3a. Intervention not under general anesthesia } \\
\text { Grade 3b. Intervention under general anesthesia }\end{array}$ & Grade 3 \\
\hline & & $\begin{array}{c}\text { Grade } 4 \text { Life-threatening complication (including } \\
\text { central nervous system)* requiring intensive-care } \\
\text { unit management } \\
\text { Grade 4a. Single organ dysfunction (including dialysis) } \\
\text { Grade 4b. Multiorgan dysfunction }\end{array}$ & Grade 4 \\
\hline \multirow[t]{2}{*}{ 4. Death } & Complications resulting in death & Patient's death & Grade 5 \\
\hline & & $\begin{array}{l}\text { Suffix "d" If the patient suffers from a complication } \\
\text { at the time of discharge, the suffix "d" (for "disabil- } \\
\text { ity") is added to the respective grade of complica- } \\
\text { tion. This label indicates the need for a follow-up to } \\
\text { fully evaluate the complication } \\
\text { *Brain hemorrhage, ischemic stroke, subarachnoidal } \\
\text { bleeding, but excluding transient ischemic attacks }\end{array}$ & \\
\hline
\end{tabular}

[15]. In contrast, studies applying the Clavien-Dindo classification report markedly higher incidences, e.g. 13.1\% (Grade $\geq 3: 4.1 \%$ ) for gynecological CLS [44], $18.4 \%$ (Grade $\geq 3: 5.2 \%$ ) for gynecological RALS [12], and $12.5 \%$ (Grade $\geq 3: 7.5 \%$ ) for general-surgical laparoscopies [43].

Nevertheless, when using similar criteria, the complication rates of CLS and RALS seem to be comparable $[6,8,13,28]$. Most publications report identical $[7,13,28]$ or lower [8] frequencies of intraoperative complications in favor of RALS, no difference $[7,8,28]$ or reduction of minor postoperative complications ( $13.9 \%$ vs. $22.8 \%$ [13]) with the aid of the robot, but similar $[8,28]$ or increased incidence of major postoperative complications [7], e.g. 5.2\% vs. $2.2 \%$ in the robotic arm of Ref. [13]. A comparison of intra- and postoperative complication rates of CLS and RALS is presented in Table VI.

\section{Mortality}

Operative mortality from any minimally invasive gynecological surgery (laparoscopy and RALS) is extremely low (1 of 6456 procedures) [15, 23]. The procedure-associated mortality of CLS is quoted at $0.02 \%(0.01-0.03 \%)$, which can be translated into an estimated risk of death of 1 in 6512 (1 : 3971-1 : 10680) laparoscopies [23]. Major vascular injuries (MVI) are responsible for $74-82 \%$ of all laparoscopy-associated fatalities, followed by (not recognized) intestinal injuries [14-27]. The mortality rate of RALS is 1 out of 5430 procedures, although 
Table V. Complexity grading systems of gynecologic laparoscopic procedures. The original nomenclature of surgical procedures remained unchanged

\begin{tabular}{|c|c|c|c|c|c|}
\hline \multicolumn{2}{|c|}{ Chapron et al. 1998 [15] } & \multicolumn{2}{|r|}{ ESGE [45] } & \multicolumn{2}{|c|}{$\begin{array}{c}\text { German Association of Gynecologic } \\
\text { Endoscopy [46] }\end{array}$} \\
\hline LEVEL & Procedures & LEVEL & Procedures & LEVEL & Procedures \\
\hline Diagnostic & Diagnostic laparoscopy & \multirow[t]{2}{*}{ Basic } & \multirow{2}{*}{$\begin{array}{c}\text { Diagnostic laparoscopy, } \\
\text { tubal sterilization, } \\
\text { cyst aspiration, } \\
\text { biopsy }\end{array}$} & \multirow[t]{2}{*}{ Type I } & \multirow[b]{2}{*}{$\begin{array}{l}\text { Diagnostic laparoscopy, } \\
\text { tubal sterilization, } \\
\text { chromopertubation, } \\
\text { simple adhesiolysis, } \\
\text { destruction of endometri- } \\
\text { osis rAFS I, or comparable } \\
\text { procedure }\end{array}$} \\
\hline Minor & $\begin{array}{l}\text { Minimal adhesiolysis (as } \\
\text { assessed by the surgeon), } \\
\text { destruction of minimal } \\
\text { endometriosis, } \\
\text { ovarian biopsies, } \\
\text { ovarian punctures, } \\
\text { tubal sterilization, } \\
\text { assisted conception } \\
\text { procedures }\end{array}$ & & & & \\
\hline Major & $\begin{array}{c}\text { Ectopic pregnancy, } \\
\text { pelvic inflammatory } \\
\text { disease, } \\
\text { polycystic ovaries, } \\
\text { benign ovarian cysts, } \\
\text { distal tubal plasty, } \\
\text { uterine suspension, } \\
\text { extended adhesiolysis, } \\
\text { moderate or severe endo- } \\
\text { metriosis }\end{array}$ & $\begin{array}{l}\text { Intermedi- } \\
\text { ate }\end{array}$ & $\begin{array}{l}\text { Salpingotomy, } \\
\text { salpingectomy, } \\
\text { oophorectomy, } \\
\text { ovarian cystectomy, } \\
\text { adhesiolysis, } \\
\text { treatment of mild-moder- } \\
\text { ate endometriosis }\end{array}$ & Type II & $\begin{array}{l}\text { Ectopic pregnancy, } \\
\text { salpingectomy, oophorec- } \\
\text { tomy, adnexectomy } \\
\text { ovarian cystectomy, } \\
\text { myomectomy for pedun- } \\
\text { culated or subserous } \\
\text { myomas (without uterine } \\
\text { reconstruction), } \\
\text { hysterectomy, } \\
\text { extended adhesiolysis, } \\
\text { destruction of endometrio- } \\
\text { sis rAFS I/II, Enzian A1/B1, } \\
\text { or comparable procedure }\end{array}$ \\
\hline \multirow[t]{2}{*}{ Advanced } & \multirow[t]{2}{*}{$\begin{array}{c}\text { Hysterectomy, } \\
\text { myomectomy, } \\
\text { lymphadenectomy, } \\
\text { colposuspension, } \\
\text { tubal sterilization reversal, } \\
\text { genital prolapse, } \\
\text { endometrial and cervical } \\
\text { cancer, } \\
\text { retroperitoneal endome- } \\
\text { triosis }\end{array}$} & Advanced & $\begin{array}{c}\text { Hysterectomy, } \\
\text { myomectomy, } \\
\text { extensive adhesiolysis, } \\
\text { treatment of severe endo- } \\
\text { metriosis, } \\
\text { treatment of urinary } \\
\text { incontinence, } \\
\text { treatment of bladder or } \\
\text { bowel injuries }\end{array}$ & Type III & $\begin{array}{l}\text { Type II procedures per- } \\
\text { formed in presence of } \\
\text { distorted anatomy, } \\
\text { intramural or intraligamen- } \\
\text { tary myomectomy, } \\
\text { destruction of endome- } \\
\text { triosis rAFS III/Enzian A2/ } \\
\text { B2/C1, } \\
\text { microsurgical distal tubal } \\
\text { reconstruction, } \\
\text { cervico- or colposacropexy, } \\
\text { or comparable procedure }\end{array}$ \\
\hline & & $\begin{array}{l}\text { Special } \\
\text { procedures }\end{array}$ & $\begin{array}{l}\text { Treatment of pelvic floor } \\
\text { disorders, } \\
\text { oncology (lymphadenecto- } \\
\text { my, radical hysterectomy, } \\
\text { axilloscopy), } \\
\text { treatment of recto-vaginal } \\
\text { nodules } \\
\text { procedures not yet de- } \\
\text { scribed }\end{array}$ & Type IV & $\begin{array}{c}\text { Radical hysterectomy, } \\
\text { lymphadenectomy, } \\
\text { destruction of endometrio- } \\
\text { sis rAFS IV/ Enzian A3/B3/ } \\
\text { C2-3/FB/FU/FI, } \\
\text { complex pelvic floor recon- } \\
\text { struction, } \\
\text { microsurgical proximal } \\
\text { tubal reconstruction, } \\
\text { reconstructive surgery for } \\
\text { congenital malformations, } \\
\text { or comparable procedure }\end{array}$ \\
\hline
\end{tabular}


Table VI. Average incidence rates of intra- and postoperative complications in gynecological laparoscopical procedures (in percent)

\begin{tabular}{|lcc|}
\hline Variable & Conventional laparoscopical surgery & Robotic-assisted laparoscopical surgery \\
\hline $\begin{array}{l}\text { Overall (intra- and } \\
\text { postoperative period) }\end{array}$ & $0.5-13 \%$ & $3.2-18.4 \%$ \\
\hline Intraoperative & $1.9 \%$ & $3.2 \%$ \\
\hline Vascular injury & $0-1.7 \%$ & $0-1.7 \%$ \\
\hline Intestinal injury & $0.13-0.5 \%$ & $0.6-2.8 \%$ \\
\hline Urinary tract & $0.5-1.7 \%$ & $1.2-3.5 \%$ \\
\hline Postoperative & $13-34 \%$ & $18.4 \%$ \\
\hline Clavien-Dindo grade 0-2 & $9 \%$ & $13.2 \%$ \\
\hline Clavien-Dindo grade 3-4 & $4 \%$ & $5.2 \%$ \\
\hline Vaginal cuff dehiscence & $0.6-1.3 \%$ & $1.6 \%$ \\
\hline Port-site metastasis & $1.0-1.2 \%$ & $1.4-1.9 \%$ \\
\hline
\end{tabular}

the available data are less robust [23]. The mortality of conventional laparoscopic hysterectomy $(\mathrm{LH})$ is $0.01 \%(0.01-0.02 \%)$, corresponding to $1: 6799$ ( 1 : 4109-1 : 11249) procedures. The highest mortality amongst non-oncological laparoscopic procedures is associated with sacrocolpopexy, reaching $0.07 \%(0-5.65 \%)$, that is $1: 1343$ (1: 18-1 : 107855) interventions [23].

The odds of death from any laparoscopic or robotic gynecologic oncology surgery is 1 in 381 (95\% Cl: $1: 306-1: 474)$, with odds at $1: 289$ ( $1: 175-1: 476)$ and $1: 476(1: 365-1: 619)$ for CLS and RALS, respectively [24]. The operative mortality rate of any type of minimally invasive hysterectomy performed for oncologic indications is 1 in 379 (95\% Cl: 1 : 304-1 : 472), with the lowest incidence of procedure-related death reported for radical hysterectomy (1 : 2049; 95\% Cl: 1 : 356-1 : 11 832), and the highest one for hysterectomy with lymph node dissection for endometrial cancer - 1 : 195 (95\% Cl: 1 : 109-1 : 349). However, these numbers should be interpreted with caution, given that patients with cervical cancer are usually younger and healthier as compared to patients with endometrial cancer, who are more often affected by multiple comorbidities and obesity [24].

The mortality data, pooled from [23, 24] and stratified by procedure and indication, are presented in Table VII.

\section{Incidence of complications according to the stage of surgery}

In the following paragraph we examine the incidence of complications related to: entering and leav- ing the abdominal cavity, and presence of the pneumoperitoneum. AEs occurring during the surgery itself will be presented in the sections "organ-related" and "instrument-related" complications.

\section{Entry-related complications}

The insufflation of $\mathrm{CO}_{2}$ using a Veress needle (VN) usually precedes the placement of trocars. The VN is typically inserted via the umbilicus, but in case of suspected adhesions or very large uteri, the abdomen can be more safely accessed via left upper quadrant (Palmer's) and supraumbilical (Lee-Huang') entry points, respectively [47-49]. Direct trocar entry (DTE) and open laparoscopic access (Hasson technique) offer non-inferior but less popular alternatives [47-49]. VN is chosen by $80 \%$ of general surgeons and $96 \%$ of gynecological laparoscopists as a standard method [16, 49]. Transuterine and trans-cul-de-sac access (both proposed for extremely obese patients) or VN insertion through the ninth or tenth intercostal space (as an alternative to Palmer's point) is reserved for rare situations and for very experienced surgeons [48, 50]. About 50\% (35-57\%) of all laparoscopic complications, especially $50-83 \%$ of serious vascular complications, $41-50 \%$ of intestinal complications, and $36 \%$ of urological injuries, occur during the initial set up: creation of the pneumoperitoneum and trocar insertion [9, 14, 15, 17, 19, 49]. Entry-related complications are significantly less common in gynecological than in general surgery (4-fold and 3-fold for bowel and combined bowel/vascular injuries, respectively [17]). Similarly, the entry-related 
Table VII. Mortality of minimally invasive surgical procedures in gynecology (data pooled from [23, 24])

\begin{tabular}{|c|c|c|c|c|}
\hline Procedure type & Procedures $(n)$ & Deaths $(n)$ & Deaths, \% $(95 \% \mathrm{Cl})$ & Deaths, odds (95\% Cl) \\
\hline All MIS procedures & 39183 & 77 & $0.26(0.21-0.33)$ & $1: 381(1: 306-1: 474)$ \\
\hline Any hysterectomy & 38619 & 77 & $0.26(0.21-0.33)$ & $1: 379(1: 304-1: 472)$ \\
\hline Radical hysterectomy & 3369 & 0 & $0.05(0.01-0.28)$ & $1: 2049(1: 356-1: 11832)$ \\
\hline Hysterectomy + lymph nodes & 3501 & 11 & $0.51(0.29-0.91)$ & $1: 195(1: 109-1: 349)$ \\
\hline Ovarian cancer & 418 & 0 & $0.15(0.01-2.29)$ & $1: 685(1: 44-1: 10971)$ \\
\hline \multicolumn{5}{|l|}{ Conventional laparoscopy: } \\
\hline All laparoscopic procedures & 9365 & 13 & $0.35(0.21-0.57)$ & $1: 289(1: 175-1: 476)$ \\
\hline Any hysterectomy & 8842 & 13 & $0.36(0.21-0.59)$ & $1: 281(1: 169-1: 469)$ \\
\hline Radical hysterectomy & 2442 & 0 & $0.05(0.01-0.4)$ & $1: 1842(1: 247-1: 13771)$ \\
\hline Hysterectomy + lymph nodes & 1334 & 0 & $0.05(0-1.59)$ & $1: 2217(1: 63-1: 79$ 448) \\
\hline \multicolumn{5}{|l|}{ RALS: } \\
\hline All robotic procedures & 27971 & 54 & $0.21(0.16-0.27)$ & $1: 476(1: 365-1: 619)$ \\
\hline Robotic hysterectomy & 27930 & 54 & $0.21(0.16-0.27)$ & $1: 476(1: 365-1: 620)$ \\
\hline Radical hysterectomy & 927 & 0 & $0.07(0-1.06)$ & $1: 1496(1: 94-1: 23$ 933) \\
\hline \multicolumn{5}{|c|}{ Surgery (CLS + RALS) for benign indications: } \\
\hline All MIS procedures & 124216 & 15 & $0.02(0.01-0.03)$ & $1: 6456(1: 3946-1: 10562)$ \\
\hline MIS hysterectomy & 119721 & 15 & $0.01(0.01-0.02)$ & $1: 6814(1: 4119-1: 11275)$ \\
\hline Laparoscopic hysterectomy & 114750 & 15 & $0.01(0.01-0.02)$ & $1: 6799(1: 4109-1: 11249)$ \\
\hline All robot procedures & 5458 & 0 & $0.02(0-1.45)$ & $1: 5430(1: 69-1: 435052)$ \\
\hline All laparoscopy procedures & 118758 & 15 & $0.02(0.01-0.03)$ & $1: 6512(1: 3971-1: 10680)$ \\
\hline Sacrocolpopexy (MIS) & 864 & 0 & $0.08(0-2.8)$ & $1: 1246(1: 36-1: 44700)$ \\
\hline Sacrocolpopexy (laparoscopy) & 757 & 0 & $0.07(0-5.65)$ & $1: 1343(1: 18-1: 107855)$ \\
\hline Adnexal surgery & 1960 & 0 & $0.04(0-2.2)$ & $1: 2245(1: 45-1: 113372)$ \\
\hline
\end{tabular}

mortality following general-surgical laparoscopies has been reported as high as $0.05 \%$ to $0.2 \%$ [49]. Earlier studies comparing open (Hasson technique) vs. closed (VN, DTE) entry modes indicated a higher number of vascular injuries with closed techniques as compared to open entry (0.8\% vs. 0\%), but no significant differences in relation to bowel injuries, gas embolism or perioperative death [9]. Surprisingly, the introduction of optical trocars did not increase the safety of abdominal entry in regard to bowel or vascular injuries [48, 49]. The latest Cochrane Review (as of 2019) did not find any differences between laparoscopic entry techniques with regard to vascular injury, visceral injury or solid organ injury and identified no evidence supporting the use of one laparoscopic entry technique over another [51]. Failed entry was less frequent with DTE as compared to VN, and no difference was observed when comparing direct VN with open-entry technique [51]. For similar reasons, the general-surgical and gynecological societies across the world do not recommend any single entry technique [52]. Nevertheless, VN-related (as compared to trocar) injuries are usually smaller (2 $\mathrm{mm}$ vs. 5-10 $\mathrm{mm}$ ), are associated with less dramatic morbidity and mortality, and result less often in malpractice claims [26]. Baggish considers "trocar or needle deviation from the midline during entry", and "insertion of trocars and needles at angles approaching $90^{\circ}$ " as the major risk factors for entry-related complications [3]. The risks associated with blind insertion of the primary trocar cannot be fully eliminated. In contrast, injuries related to secondary trocar insertion are almost always preventable, and yet every third trocar-related complication occurs during secondary trocar placement $[9,53]$. 
One of the main risk factors at the step of laparoscopic entry is periumbilical adhesions. They are rarely present $(0.7 \%)$ in never-operated-on patients; however after laparoscopy, Pfannenstiel laparotomy, and midline laparotomy they can be expected in $1.6 \%, 20 \%$, and $52 \%$ of cases, respectively [ 54 , 55]. In this context, the widespread trend towards non-closure of the peritoneum during caesarean section should by questioned. The accumulating long-term data have demonstrated that - in contrast to the slightly improved short-term outcomes - the abandoning of peritoneal closure during caesarean section results in a significantly increased likelihood of adhesion formation [56, 57], which is a known risk factor for a variety of surgical AEs, including entry-related complications.

\section{Failed entry}

The real incidence of failed laparoscopic entry depends on individual surgical experience and, eventually, the patient collective. For entry of the peritoneal cavity one, two, three or more attempts are necessary in 85-87\%, 8.5-11.6\%, 2.6-3.0\%, and 0.3-1.6\%, respectively $[48,58]$. Any additional attempt increases the probability of complications or conversion to laparotomy. Pre-peritoneal insufflation is reported in $2.7 \%$, $15 \%, 44.4 \%$, and $100 \%$ of cases, after, respectively, one, two, three, and more than three entry failed attempts [58]. The overall complication rates reported in relation to the number of unsuccessful attempts are: $0.8 \%$ to $16.3 \%$ after one attempt; $16.31 \%$ to $37.5 \%$ after two attempts; $44.4 \%$ to $64 \%$ after three attempts; and $84.6 \%$ to $100 \%$ after more than three attempts $[48,58]$.

Consequences of failed entry are preperitoneal insufflation (79\%), omental emphysema (21\%), bowel injury [10,48, 58], and failed laparoscopy (up to $3.6 \%$ in [10]).

\section{Approach-specific complications at or after completion of surgery}

\section{Intraabdominal spillage of adnexal tumors}

Intraoperative spillage occurs in 55-65\% (15$100 \%$ ) of laparoscopic removals of presumably benign ovarian cysts [59-61]. The relative risk for this event - compared to mini-laparotomy - is 5.5-fold higher [61]. The spillage probability is independent of ovarian cyst diameter [62]. Intraoperative cyst rupture is not a risk factor for reoperation, infertility, transient fever, or readmission [62]. In the case of a dermoid cyst, the risk for chemical peritonitis caused by leaked fat, sebum, hair and other tissues is statistically (up to 10-fold) increased by spillage [62], but - fortunately - this complication is extremely rare (0-0.2\%) [59, 60, 62, 63].

With respect to malignant ovarian tumors, capsule rupture and intraperitoneal spillage are noted in 22$23 \%$ of minimally invasive surgery (MIS) procedures (including CLS and RALS) [64]. Unlike for benign ovarian cysts, the larger size is a strong predictor for iatrogenic rupture of a malignant ovarian tumor in MIS [64]. The histological type of the tumor seems to impact the probability of its iatrogenic spillage, with the majority of ruptures observed in clear cell (57\%), followed by endometrioid (49\%), serous (42\%), and mucinous (32\%) carcinomas [65]. The consequence of rupture is seeding of tumor cells within the abdominal cavity and disease upstaging to FIGO Ic1 (provided the tumor was occult and confined to the ovary). This fact determines the need for chemotherapy and probably worsens the prognosis, although the latter consequence is still under debate [64]. On the one hand, the comparison of long-term outcomes in 8850 women with stage I ovarian cancer confirmed the negative impact of capsule rupture on the overall survival, both for open and MIS. Moreover, the minimally invasive approach has been independently associated with tumor rupture (adjusted relative risk, 1.17; 95\% Cl: 1.06-1.29) [64]. In contrast, recent meta-analyses showed that: a) the upstaging and cyst rupture rates are comparable in MIS and laparotomy [66], b) the negative prognostic impact of iatrogenic tumor rupture is not proven [67], and c) neither the 3-year nor 5-year disease-free survival nor overall survival differs between patients undergoing MIS and those operated on by an open approach [67-69].

Given these conflicting data, every effort to improve the preoperative diagnosis of adnexal tumors $[70,71]$ and to minimize the incidence and consequences of intraoperative tumor rupture (e.g. peritoneal washings and careful intraoperative assessment prior to oophorectomy, early conversion to laparotomy in presence of suspected ovarian tumor in a technically demanding field, use of endoscopic retrieval bags) should be taken to minimize the risk of ovarian capsule rupture during MIS $[64,65]$.

\section{Trocar-site hernias}

Trocar-site hernias (TSHs) following gynecological laparoscopies are observed after $0.1 \%$ to $1.8 \%$ 
of procedures, which is significantly lower than the frequency of incisional hernias following gynecological (2-6\%) or general-surgical laparotomy (5-20\%) [72-74]. Within these incidence rates, only $3 \%$ of TSHs are diagnosed at incision sites < $8 \mathrm{~mm} ; 11 \%$ of them at incision sites $8-10 \mathrm{~mm}$, and the majority $(86 \%)$ at sites $>10 \mathrm{~mm}$ [75]. The most dangerous complication of incisional hernia is bowel or omental incarceration. Cases of both types of complications, $5 \mathrm{~mm}$ - and $8 \mathrm{~mm}$-trocar site hernias (including omental and small bowel incarceration), following RALS have been repeatedly reported [76-78].

Risk factors for developing a trocar-site hernia are: trocar diameter > $10 \mathrm{~mm}$, use of bladed (pyramidal) trocars, prolonged operative times, as well as high parity, older age and high body mass index (BMI) of the patient $[74,79,80]$. The risk for developing an incisional hernia is three to four times higher following single-incision laparoscopic surgery [81, 82].

In gynecology, umbilical defects are more common than lateral port-site defects $[73,79,83]$ and remain in $16-56 \%$ of cases asymptomatic [79]. Traditionally, closing the fascia at incision sites $\geq 10 \mathrm{~mm}$ (or $>7 \mathrm{~mm}$ ) has been recommended $[9,80]$. On the other hand, $90 \%$ of reported trocar site hernias develop despite declared fascial closure [75, 83]. Moreover, the mounting evidence has failed to prove any benefit of the routine fascial closure of incisions under $10 \mathrm{~mm}[74,84]$. This observation is of importance, since fascial closure, like any surgical maneuver, can itself induce complications, e.g. broken needle, breakage of fascial closure device or aorta puncture $[74,85,86]$.

\section{Port-site metastases}

Port-site metastases (PSMs) are observed, respectively, in $1.0-1.2 \%$ and $1.4-1.9 \%$ of patients undergoing CLS $[87,88]$ or RALS [89-91] for any abdominal malignancy. Non-carcinomatous implants at previous trocar sites, e.g. parasitic myomas [92, 93] or ectopic trophoblast tissue [94], have also been reported.

After (predominantly therapeutic) conventional or robotic-assisted laparoscopic procedures for cervical and endometrial cancer, PSMs were diagnosed after a median time of 5 (range: 1.5-19) months, and 13.5 (range: 6-21) months, respectively [87, 91]. In the event of isolated PSM, local excision, radio-, chemo- or combined radiochemotherapy were cura- tive and no further recurrences were reported (however, the data are limited) [91].

With respect to ovarian cancer, PSMs are observed very often (in 47-49\% of patients) and very early (median: 17 days) after initial MIS (usually performed as a diagnostic procedure) [95-97]. The risk factors for developing PSM in ovarian cancer are: higher tumor stage, positive lymph node status, ascites > $500 \mathrm{ml}$, and laparoscopy performed in a non-oncological center [96]. Wound healing disorders and postoperative morbidity are significantly higher in patients with PSM (Clavien-Dindo Classification grade $\geq 3$ : 41.0 vs. $14.9 \%$ ) [96]. However, the overall survival of ovarian cancer patients classified as FIGO IV stage solely due to isolated PSM is significantly longer (58 months) as compared to FIGO IV due to other distant metastases (25 months), and (although not reaching statistical significance) longer as compared to FIGO IIIC (37 months) [98]. Ataseven et al. failed to identify PSM as an independent prognostic factor in ovarian cancer [96]. In contrast, in the study of Nunez et al. PSMs were independently associated with a worse prognosis [99]. Despite these unresolved questions, resection of previous laparoscopy port sites in patients with otherwise complete cytoreduction is advocated by most authors $[96,99]$.

The following factors can contribute to the development of PSM: physical impact of pneumoperitoneum (aerosolization of tumor cells), chemical properties of $\mathrm{CO}_{2}$, wound contamination with malignant cells (e.g. in presence of ascites or during specimen removal), "chimney effect" (leakage of gas along the trocars), local immune reactions, or improper surgical technique (frequent trocar removal and reintroduction, rapid desufflation) [88]. The fact that (both in CLS and RALS) the PSMs develop predominantly (>70\%) at the position of the tissue-manipulating (specimen-retrieval) port $[89,95,100]$ indicates that measures for preventing PSM should focus on minimizing the risk of tumor cell implantation into and minimizing tissue trauma at the trocar site, e.g. avoidance of laparoscopy in presence of massive ascites, atraumatic tissue handling, clean resection margins, use of plastic retrieval bags, reduced instrument transfers, closure of all abdominal layers including the peritoneum, removal of entire intraabdominal fluid before trocar removal, irrigation of the port site with chemotherapeutic agents or povidone-iodine solutions $[88,100]$. Unfortunately, the application of 
the preventive measures is underreported in studies and therefore their effectiveness can hardly be assessed [91]. In contrast, they have been shown to be highly effective in an animal model. Schneider et al. [100] performed a prospective randomized study for studying the impact of several protective measures on the occurrence of PSM after intraoperative injection of tumor cells into the peritoneal cavity of pigs. In the experimental arm, trocar fixation, prevention of gas leaks, rinsing of instruments with povidone-iodine, minilaparotomy protection, rinsing of trocars before removal, peritoneal closure, and rinsing of all wounds with povidone-iodine were applied. After 4 weeks, histologically confirmed PSM were found in $14 \%$ of port sites in the study group but in $64 \%$ of port sites in the control group [100].

\section{Vaginal cuff dehiscence}

The poor standing of $\mathrm{LH}$ in regard to vaginal cuff dehiscence (VCD), which was reported by earlier studies after $4.9 \%$ of laparoscopic, $3.0-4.1 \%$ of robotic-assisted, $0.29 \%$ of vaginal, and $0.12 \%$ of abdominal hysterectomies [101, 102], has been revised by the recent evidence. Contemporarily, VCD is noted after $0.11-1.27 \%$ of laparoscopic, $0.45-1.64 \%$ of robotic-assisted, $0.05-0.13 \%$ of vaginal, and $0.02-0.38 \%$ of open hysterectomies [103-107]. As of 2021, the occurrence of VCD following total LH (TLH) can be expected in $0.64-1.35 \%$ of cases, and after robotic hysterectomy in approximately $1.6 \%$ of cases $[108,109]$. The manifestations of VCD are: pelvic pain, abnormal vaginal discharge and bleeding, peritonitis, and - in 30-68\% of cases - omentum or bowel protruding from the vagina [101-103, 107]. Sexual intercourse earlier than 8 weeks after $\mathrm{LH}$ is the main risk factor for VCD, regardless of how (CLS or RALS) and why (benign or oncologic indications) the hysterectomy was performed [101-104, 108, 109]. In oncological patients, vaginal brachytherapy and chemotherapy have been identified as further risk factors for VCD [103, 109, 110].

Surgical risks include extensive or inadequate application of electrosurgical technique (e.g. coagulation instead of cutting mode for vaginal incision [111]), transvaginal closure of the vault, use of single instead of continuous stiches, postoperative infection and supravaginal hematoma [106, 108]. Patient-related risks for developing VCD are: premenopausal status, smoking habit, and preexistent endometrio- sis [103, 105-113]. No differences in the frequency of VCD were noted in relation to the use of barbed versus non-barbed suture (polyglactin 910) [114] or single-layer versus double-layer barbed suture [108, 115], with the exception of RALS, where the use of barbed sutures was associated with better healing and fewer separations of the vaginal cuff $[108,116]$.

\section{Pneumoperitoneum-related complications}

\section{Subcutaneous emphysema, pneumothorax and hypercarbia}

Using computed tomography, residual pneumoperitoneum can be detected in $70 \%$ and subcutaneous emphysema in $56 \%$ of patients $24 \mathrm{~h}$ after laparoscopy [117]. Grossly detectable subcutaneous emphysema occurs in $2.3 \%$, pneumothorax/pneumomediastinum in $1.9 \%$, and hypercarbia in $5.5 \%$ of patients [118]; however, all conditions resolve spontaneously within 2-3 days. Operative times $>200 \mathrm{~min}$ elevate the chance for hypercarbia (2-fold), subcutaneous emphysema (5-fold) and pneumothorax/ pneumomediastinum (20-fold) [118].

\section{Gas embolism}

Gas embolism following damage of large retroperitoneal vessels or high-pressure insufflation into the hepatic venous system is exceptionally rare but usually fatal $[17,19]$. Otherwise, minimal amounts of $\mathrm{CO}_{2}$ diffuse into capillary vessels during every laparoscopy and are - due to good solubility of $\mathrm{CO}_{2}$ - clinically irrelevant. Kim et al. observed detectable gas within venous blood samples in $100 \%$ of patients undergoing TLH, and bubbles filling more than half of the right side of the heart at transesophageal echocardiography in $37.5 \%$ of patients. However, no patient in this study developed hemodynamic instability or electrocardiogram changes despite confirmed venous air embolism [119].

\section{Postlaparoscopic shoulder pain}

Postlaparoscopic shoulder pain (PLSP) is reported by $50-80 \%$ of patients undergoing laparoscopic interventions. PLSP is a referred pain caused by chemical irritation of the phrenic nerve by $\mathrm{CO}_{2}$ and by mechanical distention of the parietal peritoneum and liver capsule. PLSP usually lasts 1-3 (occasionally up to 7) days [120, 121]. The main risk factor for developing PLSP is residual intraabdominal $\mathrm{CO}_{2}$; 
therefore maneuvers improving its elimination at the end of surgery, such as gas suction and saline instillation before leaving the abdomen as well as the pulmonary recruitment maneuver, reduce the incidence and severity of PLSP [121-125].

\section{Complications related to laparoscopic instruments}

\section{Morcellator-associated complications}

Laparoscopic evacuation of a bulky specimen presumes its fragmentation. Morcellation is an essential part of myomectomy, supracervical LH, TLH for large uteri, or non-suspicious ovarian fibroids [126-128]. For cutting or peeling the specimen, morcellators use mechanical forces (rotating blade) or, occasionally, an integrated electrosurgical device $[126,129]$. The use of morcellators harbors three types of risks: direct injury to adjacent organs, intraperitoneal spread of a benign disease, and inadvertent morcellation of a malignant tumor [128-132].

\section{Direct injury}

The morcellator's blade rotates with 500-1000 revolutions per minute. The diameters of the blades vary between 12 and 13, and $15 \mathrm{~mm}$ [126]. Devised for quick removal of large tissue portions, morcellators can cause severe injuries, which affect in $47 \%$ of cases the intestine, in $41 \%$ the vascular system, in $20 \%$ multiple organs, and in $10 \%$ result in the patient's death [126, 129-131]. In every third case, the complication remains undetected during surgery. "Lack of experience", "lack of training", and "lack of control", followed by poor visualization or device malfunction, were identified as risk factors for morcellator-related injuries [129].

\section{Complications following morcellation of benign specimen}

After LH or myomectomy, which includes the process of morcellation, iatrogenic endometriosis develops in $1.4 \%$, adenomyosis in $0.57 \%$, isolated parasitic myoma in $0.9 \%$, and disseminated peritoneal leiomyomatosis in $0.1 \%$ of cases [128]. Parasitic myomas and adenomyomas can develop at distant localizations, e.g. the colon, diaphragm, omentum or umbilicus, and can reach a diameter $>10 \mathrm{~cm}$ [130], predominantly in premenopausal women. The median time to presentation is 5 years [128].

\section{Inadvertent morcellation of a malignant tumor}

The rates of any occult malignancy encountered in morcellated uterine specimens are reported between $0.25 \%$ ( 1 in 400) and $0.43 \%$ (1 in 230) [131, 132]. When limited to uterine leiomyosarcoma (LMS), the numbers range from $0.05 \%$ (1 in 2000) [133] to $0.14 \%$ (1 in 700) [127]. Unexpected LMS morcellation complicates $0.15 \%$ (1 out of 650 ) of hysterectomies and $0.08 \%$ (1 out of 1306) of myomectomies [127]. In uterine leiomyosarcoma (LMS), morcellation increases the overall recurrence rate (62\% vs. $39 \% ; \mathrm{OR}=3.16 ; 95 \% \mathrm{Cl}: 1.38-7.26)$ and the intra-abdominal relapse (39\% vs. $9 \%$; OR $=4.11$; 95\% Cl: 1.92-8.81), as well as the mortality rate (48\% vs. $29 \%$; OR $=2.42 ; 95 \% \mathrm{Cl}: 1.19-4.92$ ) [134], whilst no survival differences were observed for patients with morcellated low-grade endometrial stromal sarcoma [135] or occult endometrial carcinoma [136]. The risk of occult LMS is elevated in black women, patients aged $>40$ years, patients with a history of retinoblastoma, women presenting with a rapidly growing, large $(\geq 8 \mathrm{~cm})$, solitary, highly vascularized (peripheral and central), heterogeneous myometrial tumor with central necrosis or degenerative cystic changes [127, 137]. In case of uncertainty, magnetic resonance imaging with contrast enhancement, determination of lactate dehydrogenase and its isoenzyme type 3 in serum, as well as endometrial sampling prior to surgery, may help to better distinguish between LMS and fibroid [138, 139].

In 1995 the American Food and Drug Administration (FDA) approved the first power morcellator for the US market to be used for gynecological laparoscopic procedures, with special indication for the removal or morcellation of uterine myomas [140]. However, in 2014, after the globally discussed case of iatrogenic LMS morcellation in the patient Amy Reed, the FDA released a warning, followed by a recommendation for limiting the use of laparoscopic power morcellation [140, 141]. When morcellation is appropriate, power morcellators should be used only with compatible containment systems [141]. Additionally, on 29 December 2020 the FDA issued a final guidance for "Product Labeling for Laparoscopic Power Morcellators", maintaining the warning that "laparoscopic power morcellators are contraindicated for removal of uterine tissue containing suspected fibroids in patients who are: post-menopausal or over 50 years of age, or candidates for en bloc tissue 
removal through the vagina or via a mini-laparotomy incision" [141].

Nevertheless, contained tissue extraction techniques, which are recommended to reduce the risk of specimen spillage [141, 142], have not been proven satisfactory to date. The spillage of dye or tissue is noted in $9 \%$ of cases with a macroscopically intact bag [143], and bag perforations are reported in 13\% of contained morcellations [144]. Therefore, according to the Cochrane review of 2020 the benefit of "in-bag" morcellation remains unproven [145].

\section{Instrument-related complications: energy}

Energy-based surgical devices (ESDs) comprise electrosurgical, ultrasonic, hybrid (electrosurgical and ultrasonic), and laser-based instruments [146]. All types of ESDs produce thermal effects. The ranges of working temperatures of ESDs are (depending on instrument model, power setting and application time): $100-400^{\circ} \mathrm{C}$ for monopolar instruments, $80-120^{\circ} \mathrm{C}$ for bipolar instruments, $60-100^{\circ} \mathrm{C}$ for advanced bipolar systems, $60-200^{\circ} \mathrm{C}$ for ultrasonic devices, and $100-220^{\circ} \mathrm{C}$ for the hybrid device Thunderbeat [146-148]. The lateral thermal spread reaches $2-22 \mathrm{~mm}$ for monopolar instruments and 2-6 $\mathrm{mm}$ for conventional bipolar instruments. The lateral thermal spread of advanced bipolar systems is reported at 2-5 $\mathrm{mm}$ for Ligasure, 1-1.7 $\mathrm{mm}$ for Enseal and 1.5-6 mm for PK PlasmaKinetics. Among ultrasonic devices, the Harmonic Scalpel produces 1-4 mm lateral spread, and the hybrid device Thunderbeat 2-3 mm [146-148]. The thermal effects of the main ESD types are summarized in Table VIII.

ESD-related complications are reported after $0.2-0.5 \%$ of laparoscopic procedures [22, 53, 146], being in $70 \%$ recognized post-operatively $[22,53$, $149,150]$. Every fourth laparoscopic AE - including $26-29 \%$ of all bowel injuries and $33-50 \%$ of ureter injuries - $[22,53,149,150]$ is created by ESD. The majority of ESD-related complications are preventable [151]. They happen usually due to inappropriate use and can cause harm at sites distant from the surgeon's field of view [146, 149-153]. The most common scenarios are inadvertent ESD activation, instrument defects (e.g. insulation failure), or ignorance of physics laws (e.g. lateral temperature spread, direct coupling, capacitive coupling) [146, 152-154]. Monopolar - as compared to bipolar and ultrasonic - instruments usually cause more extensive injuries [146-148, 150]. Insulation failure and capacitive coupling are the most common reasons for ESD-related injuries in laparoscopy: 18\% of insulation defects are located in the critical parts of the instrument most likely to create a catastrophic electrosurgical injury [152, 154].

\section{Instrument-related complications: skin burns}

Skin burns (SB) during laparoscopy are rare, but almost always related to improper ESD use, reduced attention of the surgeon or, less frequently, to device malfunction [151]. As in the case of other ESD-associated complications, the use of monopolar energy is associated with the highest risk of injury. However, all devices producing thermal effects can cause harm following unprotected and uncontrolled contact with skin. Saaiq et al. grouped iatrogenic intraoperative SB according to their mechanism:

a) direct contact burns from the active electrode resting on the patient's skin or contacting the operating staff,

b) burns at the site of the grounding electrode,

c) burns resulting from electrode heating of pooled solutions such as spirit,

d) burns occurring outside the operative field as a result of circuits generated between the active electrode and an alternate grounding source [155].

Table VIII. Thermal effects depending on ESD type

\begin{tabular}{|lcc|}
\hline Energy modality (ESD type) & Working temperature range $\left[{ }^{\circ} \mathrm{C}\right]$ & Thermal spread within tissue $[\mathrm{mm}]$ \\
\hline Monopolar & $100-400$ & $2-22$ \\
\hline Bipolar (conventional) & $80-120$ & $2-6$ \\
\hline Bipolar (advanced) & $60-100$ & $1-7$ \\
\hline Ultrasonic & $60-200$ & $1-4$ \\
\hline Hybrid (bipolar-ultrasonic) & $100-220$ & $2-3$ \\
\hline
\end{tabular}

ESD - energy-based surgical device. 
Alternative site burns occur when the patient's skin is in contact with conductive materials (e.g. metallic OP-table elements or metallic i.v. pole) and the electric currents return to the ground [156]. Severe SB can result from direct or capacitive coupling to metal cannulas or capacitive coupling to the skin edge across plastic cannulas [157]. The "active electrode monitoring" technology reduces the chance for alternate site burns resulting from e.g. faulty application or detachment of the return pad, but it does not fully eliminate the possibility of SB. Apart from monopolar technology, accidental severe SB have been reported as a result of inadvertent activation of bipolar instruments resting on the patient's skin or wet surgical drapes [158]. The use of alcoholand spirit-based skin preparation solutions can further increase the risk of fires and burn injuries [151, 155]. In addition, fiberoptic cables represent another source of serious iatrogenic SB: their tips heat to $120-267^{\circ} \mathrm{C}$, the minimal distance between skin and light source required for producing skin necrosis is $3 \mathrm{~mm}$, and surgical drapes char after 3-6 s exposure to the tip of the cable [159].

\section{Instrument-related complications: equipment failure}

About $40 \%$ of CLS procedures are complicated by at least one equipment failure $[152,160]$. The bipolar cable and forceps account for $31-42 \%$ of instrument malfunctions [152, 160]. Insulation failure (IF) affects $19-37 \%$ of ESDs, reaching $39 \%$ in monopolar instruments [161, 162]. IF is localized in $40-54 \%$ of cases at the distal third of the instrument and is more frequent in reusable instruments [154, 162]. Intense exploitation of reusable instruments, predominant use of high voltage modes, multiple passages through trocars and frequent mechanized sterilization facilitate the development of IF [154]. Fluid, gas, and light transmission complicates $36.2 \%$ of laparoscopies, while imaging defects are noted in $12 \%$ [160]. In every fifth case equipment failures can potentially cause severe harm to the patient [160]. Time wasted due to the malfunctions in laparoscopy accounts for $1.4-7 \%$ of the overall surgical time $[152,160]$. Causes of malfunctions are in $45 \%$ of cases limited to the instrument and in $43-47 \%$ were the result of erroneous combination of elements. Human decisions contribute to $43-50 \%$ of instrument failures [152, 160]. The ignorance about function and safety principles of ESD among laparoscopic surgeons is at a similar level [148, 163].

Despite technical developments, equipment malfunctions are not infrequent in RALS [164, 165]. Event logs of the da Vinci (Si) systems registered robotic malfunctions in $5 \%$ of operations, e.g. errors of pressure sensors in the robotic arms, unrecoverable electronic communication, illuminator- or battery-related errors [165]. An analysis of FDA data revealed the following distribution of instrument malfunctions - impacting patient safety through injuries or procedure interruptions - in RALS: falling of burnt/broken pieces of instruments into the patient (14.7\%), electrical arcing of instruments (10.5\%), unintended operation of instruments (8.6\%), system errors (5\%), and video/imaging problems (2.6\%) [164].

\section{Instrument-related complications: lost or broken surgical items}

The occurrence of intraoperatively retained instruments is reported after $0.06-0.11 \%$ of minimally invasive procedures [166]. The most often retained surgical instrument is the surgical needle - lost (or broken up) either in the surgical field or within the patient's abdominal wall, arrested within the trocar valve or sucked away via the suction device [166170]. Broken tips of laparoscopic stitch devices or disintegrated laparoscopic instruments have also been reported [167, 168]. A survey performed among minimally invasive surgeons in the United States revealed that $64 \%$ of them experienced a needle loss (NL). Most respondents (90\%) reported 1 to $5 \mathrm{NL}$ incidents during their careers, and the remaining $10 \%$ reported 6 to 20 incidents or more. Typically, needle removal through a trocar and laparoscopic suturing were the common situations resulting in NL [170]. Risk factors for NL during MIS are: high BMI, concurrent use of more than one needle, equipment malfunction, and emergency [166]. RALS and single-site surgery are associated with a higher likelihood of NL than CLS [166]. An overseen NL can have devastating long-term consequences for the patient (bowel and vessel perforations, development of fistulas, chronic pain, subsequent surgery) and for the surgeon (medical and legal consequences) [166]. Fortunately, NL is usually noticed immediately. However, due to limited vision and restricted instrument flexibility in laparoscopy, finding the needle (or a part of it) can be more 
demanding than in open surgery [170]. When inspection of the surgical field and abdominal incisions, revision of trocars and suction devices, and application of a laparoscopic magnet (provided its availability) fail, additional patient burdens can result from X-ray exposure and laparotomy [166, 167].

\section{Complications in relation to affected organs}

\section{Vascular injuries}

The perforation of abdominal wall vessels (inferior and superficial epigastric arteries and muscular perforating vessels) by secondary trocars is reported in $0.3 \%$ to $2.5 \%$ of procedures $[9,21,171]$. The inferior epigastric vessels are the most affected, comprising $48 \%$ (95\% Cl: 40-55) of all vascular injuries [21]. The use of sharp pyramidal trocars elevates this risk of abdominal wall vessel injury [9].

Injuries to large retroperitoneal (aorta, vena cava and the iliac) vessels (usually summarized as "MVI") occur in $0.2 \%$ to $1.0 \%$ of procedures, with the most quoted rate of $0.5 \%[9,14,19,172]$. Amongst large retroperitoneal vessels, the right iliac arteries are affected in $41-48 \%$ of cases, followed by the right iliac veins (38\%), left iliac veins (29\%), aorta (13-25\%), inferior vena cava (6-11\%) and mesenteric vessels (6-17\%) [18-21, 173]. In 50-83\% of cases, MVI occur during laparoscopic entry [14-21]. VN is causative for $M V I$ in $6-46 \%$, trocars in $54-83 \%$ [9, 14, 16-18, 26, 27], and scalpel (skin incision) in up to $6 \%$ of cases [174]. Higher frequency and severity of $\mathrm{MVI}$ were reported by disposable (as compared to reusable) trocars $[9,18]$. Secondary trocar insertion accounts for $6-37 \%$ of MVI $[9,18]$. Very low BMI and periumbilical adhesions elevate the risk for $\mathrm{MVI}$ at the entry stage [173]. In $10-20 \%$ of cases, MVI is caused by ESDs, followed by dissecting instruments or stapling devices [18-21]. Every fourth MVI occurs during diagnostic procedures [15, 18], whereas lymphadenectomy and hysterectomy are associated with the highest risk for MVI [18-21]. While injuries to the abdominal vessels can be commonly managed laparoscopically, the repair of the great retroperitoneal vessels usually requires (in at least $88 \%$ of cases [21]) an immediate laparotomy [3, 19, 172]

Major vascular injuries (MVI) are associated with a $6-31 \%$ mortality rate $[16,19,20,172]$ and responsible for $74-82 \%$ of all laparoscopy-related deaths $[23,27,52]$. Venous injuries are more frequently lethal than the arterial ones [18]. Collateral damage to adjacent structures (small bowel, ureters, nerves, suturing the wrong vessel, etc.) happens concurrently or sequentially in every second case of MVI $[20,26]$. The most recent systematic review of King et al. [21] reported a surprisingly low MVI-related mortality rate of $1.1 \%$ (2 deaths from $179 \mathrm{MVI}$ in 197062 laparoscopies), most likely due to applied reporting criteria: injuries to the inferior epigastric vessels (85/179) and "not otherwise specified" vessels (64/179) were considered as MVI, so laparoscopic-oncological procedures were excluded from the study [21].

\section{Intestinal injuries}

The incidence of gastrointestinal injuries (GI-I) following gynecological CLS is estimated at 1:769 (0.13\%; 95\% Cl: 0.12-0.14\%), with an incidence range of $0.06-0.5 \%[9,22,53,149,175]$. The incidence of $\mathrm{Gl}-\mathrm{I}$ in connection with RALS is $1: 160$ (0.62\%; $95 \% \mathrm{Cl}: 0.50-0.76 \%)$, with an incidence range of $0.7 \%$ to $2.8 \%$ [12]. The robotic hysterectomy for benign and malignant is associated with GI-I rates of 1 in 262 and 1 in 156, respectively [176].

In CLS, the small intestine is involved in 34-62\% of GI-I, followed by large bowel (39-48\%), and stomach (1.6-6\%) [22, 53, 149, 175]. Ileum (accounting alone for $48 \%$ of $\mathrm{GI}-\mathrm{I}$ ) is the predominantly affected part of the small intestine, whereas the sigmoid (with 22-29\%) is the most affected part of the large bowel $[53,175]$. The distribution of GI-I in RALS is more equal, with the rectum and large bowel being affected in $37.5 \%$ each, followed by small intestine injuries reported in $24 \%$ of cases [176].

Similarly to MVI, 55\% (32-77\%) of all GI-I in CLS and $67 \%$ of GI-I in RALS occur at the start of the surgery (VN or trocar insertion, creation of pneumoperitoneum) [14, 17, 22, 53, 149, 175, 176], with $77 \%$ of small bowel and $41 \%$ of large bowel injuries complicating the initial set up of CLS [53]. Disposable trocars are associated with more frequent injuries (47\%) as compared to reusable or other trocar types [53]. A further $45 \%$ (23-57\%) of Gl-I occur during the main part of surgery, with - unlike entry-related complications - the large bowel being significantly more frequently involved as compared to the small bowel (60\% vs. 25\%, respectively) [22, 53, 175]. The causative factor for $26-34 \%$ of bowel lesions is ESD, whereas mechanical - dissecting, grasping or morcellating - instruments are involved in 15-20\% of GI-I [22, 53, 149]. Among ESD, monopolar instru- 
ments are responsible for $43 \%$ of bowel injuries [53] ESD are typically causative for late-presenting complications. The main risk factors for bowel injury are adhesions and/or previous laparotomy, noted in 70\% of GI-I [53, 149]. The risk of laparoscopic bowel injury increases with surgical complexity and is estimated at $0.07 \%(0.05-0.1 \%)$ for diagnostic and minor procedures, $0.2 \%(0.17-0.24 \%)$ for major procedures such as endometriosis surgery, $0.39 \%(0.34-0.45 \%)$ for any form of $\mathrm{LH}$, and $1-1.3 \%(0.43-2.3 \%)$ for laparoscopic sacrocolpopexy $[22,177]$. The overall mortality rate associated with bowel injury at CLS is $0.8 \%$ (0.36-3.6\%), almost exclusively resulting from delayed diagnosis [22, 53, 149]. Delayed detection of bowel injury increases the mortality rate to $3.2-3.6 \%$ [22, 149]. Unfortunately, more than half (41-84\%) of $\mathrm{Gl}-\mathrm{I}$ following CLS are diagnosed postoperatively $[22,53,149,175]$. The median time to diagnosis is 3 (1-13) days [22], with $70 \%$ of small bowel and $50 \%$ of large bowel perforations being diagnosed $>48 \mathrm{~h}$ after surgery [53, 149]. A fortunate reversal trend has been reported for RALS, where $87 \%$ of reported $\mathrm{GI}-\mathrm{I}$ were recognized at the time of surgery and in the majority of cases (58\%) could also be managed laparoscopically. As a consequence, a very low mortality $0.02 \%$ (95\% Cl: 0.01-0.07\%) - has been reported for GI-Is associated gynecological RALS [176].

\section{Urinary tract injuries}

Gynecological procedures are responsible for the majority (52-82\%) of all iatrogenic urinary tract injuries (UTIS) [178-180]. In separate analyses, UTIs are reported in $0.5 \%(0.03 \%$ to $1.7 \%)$ of gynecological laparoscopies [9, 178, 181, 182] and 2.1\% (1.2\% to $3.5 \%)$ of gynecological RALS [12], respectively. A recent systematic review did not confirm significant differences between the two approaches [180].

After exclusion of oncological and urogynecological procedures, the overall incidence of UTI following CLS for benign indication is about 0.3\% (0.03-5.8\%) [182]. Wechter et al. analyzed RALS-associated UTIs with regard to type and complexity of the procedure, and observed the following frequencies: $0.5 \%$ in benign simple, $2.7 \%$ in benign complex, $3.2 \%$ in oncological, and $5.8 \%$ in urogynecological RALS [12].

Amongst UTIs, the bladder is three times more often affected than the ureter (in $0.24 \%$ vs. $0.08 \%$, respectively). Separating the bladder from the uterus at hysterectomy or during adhesiolysis accounted for $42 \%$ of all bladder injuries, followed by primary (30\%), and secondary trocar insertion (6\%) [150]; therefore every third bladder injury is related to laparoscopic entry [150]. ESDs are responsible for $45 \%$ and $33-48 \%$ of bladder and ureteral injuries, respectively $[150,182]$. The mechanism of ureteral injury involves laceration, partial or complete transection, ligation or kinking with a suture, crushing from a clamp, thermal injury and ischemia from devascularization [180].

With regard to CLS procedures, $\mathrm{LH}$ and laparoscopically assisted vaginal hysterectomy (LAVH) represent, with $1.8 \%$ and $1.0 \%$, respectively, the highest rates of UTI [182]. If restricted to publications from 2003-2013, the overall incidence of UTI after LH was estimated at $0.73-0.84 \%$. The bladder injury rates range from $0.05 \%$ to $0.66 \%$, and the ureteral injury rate ranged from $0.02 \%$ to $0.4 \%$ across procedure types [181]. The TLH and laparoscopic-assisted vaginal hysterectomy (LAVH) are associated with a higher proportion of bladder compared to ureteral injuries, whereas the laparoscopic supracervical hysterectomy (LASH) is complicated more frequent by ureteral injury [181]. Laparoscopic radical hysterectomy is associated with significantly higher risk of urological complications at $3.8 \%$, with injuries to the bladder occurring in $2.5 \%$, and to the ureter in $1.3-1.8 \%$ of surgeries [183]. Vesicovaginal fistulas and ureterovaginal fistulas accounts for $3.44 \%$ and $2.35 \%$ of UTI after LH [181].

Bladder injuries are diagnosed in $45-85 \%$ during surgery, whereas ureteral injuries in only 3-12\% (0$40 \%$ ) of cases [150,181, 182]. Injuries to other parts of the urinary tract (urethra, kidney) are casuistic, e.g., accidental kidney morcellation [129] or renal calyx rupture following ureter injury were reported [184].

Peritoneal (e.g. post-cesarean) adhesions are the main risk factor for bladder injury. Endometriosis increases the risk of ureteral complications. The overall frequency of UTI is increased in patients with pelvic malignancy, broad ligament myomas, or being operated on by low-volume surgeons [150, 181, 182].

\section{Neurological complications}

Central nervous complications after laparoscopic surgery are usually secondary to anesthesiological or catastrophic surgical complications, e.g. cerebral ischemia following exsanguination [26] or gas embolism [19]. In contrast, laparoscopic surgeons are quite often - in 1-5\% of cases - faced with postoperative peripheral neuropathies [185-187]. Predominantly, they are caused by patient mal-positioning of 
the patient, insertion of trocars or closure of lower lateral trocar sites, intraoperative nerve entrapment, transection or thermal damage, or nerve compression following hematoma formation [185, 186, 188, 189]. Pre-existing risk factors for postoperative nerve malfunctions include previous peripheral neuropathies, diabetes mellitus, peripheral vascular disease, and extreme BMI [185, 190-192].

The overall incidence of intraoperative peripheral nerve injury in urological, gynecological and colorectal RALS is $0.16-10.0 \%$. Usually, the symptoms appear immediately after surgery [189]. In the retrospective study of Shin et al., the occurrence of abdominal wall nerve injury during laparoscopic gynecological surgery was observed in $4.9 \%$ of procedures [190]. In CLS, nerves of the lower limbs (1.5$1.8 \%)$ are more frequently affected than those of the upper limbs (0.02-0.16\%) [186]. In RALS, upper and lower extremity nerve injury is observed after $0.25-1.8 \%$ and $0.3-2 \%$ of procedures, respectively [187]. Inappropriate patient positioning in the Trendelenburg position is the most common cause of nerve injuries of the upper extremity: abduction of arms $>90^{\circ}$, bean bag use and improper placement of shoulder restraints (resulting in excess pressure over the acromioclavicular joint) are the main risk factors for upper limb neuropathies [187, 189, 191]. Inaccurate lithotomy positioning is the most common cause of lower extremity injuries [189-192]. The common peroneal, sciatic, and femoral nerves are affected in $81 \%, 15 \%$, and $4 \%$ of cases, respectively [192]. The common peroneal nerve, which runs very close laterally to the head of the fibula, can be injured following inappropriate placement of the patient's legs in the stirrups, while extreme flexion of the hip may cause femoral nerve injury [191]. The use of candy cane stirrups is associated with a threefold increased risk of lower extremity postoperative neuropathy compared with boot stirrups [193]. Low patient's BMI, prolonged time spent in the lithotomy position, and insufficient padding of leg supports are additional risk factors for perioperative lower limb neuropathies [187]. Injury to the ilioinguinal and iliohypogastric nerves typically occurs during lateral trocar insertion or following nerve entrapment during fascial closure of the lateral ports [190]. Hypogastric nerves, the sciatic nerve, the obturator nerve, and the posterior hypogastric plexus may be at risk during deep endometriosis surgery or pelvic lymphadenectomy [194].

\section{Vaginal lacerations}

Vaginal lacerations in CLS or RALS occur due to forced removal or intravaginal morcellation of a large uterus [195], the use of an oversized uterine manipulator cup [196] or vigorous instrumental manipulation within a narrow or atrophic vagina [197]. The incidence of vaginal lacerations has been reported as high as $0.8 \%$ for RALS [198], and $0.7-1 \%$ for CLS (e.g. $1 \%$ for TLH [199] and $0.7 \%$ for radical LH in the LACC trial [32]).

\section{Malpractice claims}

Gynecological surgery accounts for a high proportion of malpractice claims, independently of health and legal systems [200-203]. In a high proportion of cases, non-adherence to fundamental safety principles is responsible for the surgical mishap and its legal consequences [151, 204].

The majority of claims (82\%) result from visceral and/or vascular injuries, especially to the bowel (39$40 \%$ ) and ureters (20\%) [202, 203]. Whilst intestinal injuries are usually not related to a specific procedure, the vast majority (92\%) of ureter injuries occur during LH or adnexal surgery. Entry-related complications account for $38 \%$ of claimed injuries [26, $175,202,204]$. Among them, trocar-related injuries are by far the most common (78\%), as compared to VN $(16 \%)$ or blunt cannula $(6 \%)[26,203]$. In a Dutch evaluation, a surprisingly high proportion (77\%) of the claims were filed after non-advanced procedures: adnexal surgery was responsible for the highest proportion of claims (34\%), followed by LH (20\%), diagnostic laparoscopy (19\%), and laparoscopic sterilization (16\%). In the same study, only $20 \%$ of complications were identified intra-operatively, whereas 30\% were diagnosed in the early postoperative phase, and $50 \%$ after discharge [202]. Therefore, it is not surprising that delayed diagnosis was the most frequently $(33 \%)$ reported reason for financial compensation, followed by negligence during surgery (26\%), consequences of the event itself $(20 \%)$, and incomplete informed consent $(9 \%)[26,202]$.

\section{Complication prevention - chances and opportunities}

The majority of complications are of a surgical nature and every second is potentially preventable [205]. Although these facts have been recognized for several years, the situation still remains the same. 
Especially the safety of laparoscopic entry and that of ESD use could be reduced through the sufficient knowledge of anatomy and surgical instruments and adherence to basic laparoscopic principles [146, 204]. Given that these two areas are responsible for the vast majority of complications and catastrophes, it is confusing why some surgeons simply ignore these facts $[3,9,151,162,163,204]$. Nevertheless, several ways to improve patients' security and surgical proficiency have been noted during the last two decades, especially multi-level certifications programs offered by national and international societies $[45,46]$ as well as modern, scientifically sound concepts of laparoscopic training. Sufficient knowledge of anatomy and surgical instruments, ability to anticipate the risks and to manage unexpected difficulties, paralleled by training on body donors, pelvitrainers or virtual simulators, seem to be the right way to optimize the surgical outcome and to minimize patients' suffering caused by AEs [206, 207].

\section{Conclusions}

The majority of severe laparoscopic complications occur during laparoscopic entry. Amongst surgical instruments, ESDs are involved in every fourth complication. In a very high proportion of cases, complications (especially those affecting the bowel and ureter) are detected postoperatively. Delayed diagnosis increases the mortality and the risk for malpractice claims. However, every second complication is preventable: the adherence to basic surgical principles as well as awareness of potential hazards of MIS could protect the patients from inadvertent harm. The ability to define surgical complications and the knowledge about their incidence and risk factors are necessary for consideration of treatment options, patient counseling and to obtain informed consent.

\section{Conflict of interest}

The authors declare no conflict of interest.

\section{References}

1. Alkatout I, Biebl M. Recent advances in laparoscopy. J Clin Med 2021; 10: 131.

2. Chen R, Su Z, Yang L, et al. The effects and costs of laparoscopic versus abdominal myomectomy in patients with uterine fibroids: a systematic review and meta-analysis. BMC Surg 2020; 20: 55.
3. Baggish MS. Major laparoscopic complications: a review in two parts. J Gynecol Surg 2012; 28: 315-32.

4. Keller DS, Delaney CP, Hashemi L, et al. A national evaluation of clinical and economic outcomes in open versus laparoscopic colorectal surgery. Surg Endosc 2016; 30: 4220-8.

5. Capozzi VA, Sozzi G, Gambino G, et al. Laparoscopy versus laparotomy for surgical treatment of obese women with endometrial cancer: a cost-benefit comparative analysis. Mol Clin Oncol 2019; 11: 335-42

6. Alkatout I, Mettler L, Maass N, et al. Robotic surgery in gynecology. J Turk Ger Gynecol Assoc 2016; 17: 224-32.

7. Lawrie TA, Liu H, Lu D, et al. Robot-assisted surgery in gynaecology. Cochrane Database Syst Rev 2019; 4: CD011422.

8. Wang J, Li X, Wu H, et al. A meta-analysis of robotic surgery in endometrial cancer: comparison with laparoscopy and laparotomy. Dis Markers 2020; 2020: 2503753.

9. Magrina JF. Complications of laparoscopic surgery. Clin Obstet Gynecol 2002; 45: 469-80.

10. Fuentes MN, Rodríguez-Oliver A, Naveiro Rilo JC, et al. Complications of laparoscopic gynecologic surgery. JSLS 2014; 18 : e2014.00058.

11. Chapron C, Fauconnier A, Goffinet F, et al. Laparoscopic surgery is not inherently dangerous for patients presenting with benign gynaecologic pathology. Results of a meta-analysis. Hum Reprod 2002; 17: 1334-42.

12. Wechter ME, Mohd J, Magrina JF, et al. Complications in robotic-assisted gynecologic surgery according to case type: a 6-year retrospective cohort study using Clavien-Dindo classification. J Minim Invasive Gynecol 2014; 21: 844-50.

13. Barrie A, Freeman AH, Lyon L, et al. Classification of postoperative complications in robotic-assisted compared with laparoscopic hysterectomy for endometrial cancer. J Minim Invasive Gynecol 2016; 23: 1181-8.

14. Champault G, Cazacu F, Taffinder N. Serious trocar accidents in laparoscopic surgery: a French survey of 103,852 operations. Surg Laparosc Endosc 1996; 6: 367-70.

15. Chapron C, Querleu D, Bruhat MA, et al. Surgical complications of diagnostic and operative gynaecological laparoscopy: a series of 29,966 cases. Hum Reprod 1998; 13: 867-72.

16. Vilos GA. Litigation of laparoscopic major vessel injuries in Canada. J Am Assoc Gynecol Laparosc 2000; 7: 503-9.

17. Molloy D, Kaloo PD, Cooper M, et al. Laparoscopic entry: a literature review and analysis of techniques and complications of primary port entry. Aust N Z J Obstet Gynaecol 2002; 42: 246-54.

18. Baggish MS. Analysis of 31 cases of major vessel injury associated with gynecologic laparoscopy operations. J Gynecol Surg 2003; 19: 63-73.

19. Sandadi S, Johannigman JA, Wong VL, et al. Recognition and management of major vessel injury during laparoscopy. J Minim Invasive Gynecol 2010; 17: 692-702.

20. Baggish MS. Sixty-four cases of major vessel injury associated with laparoscopic surgery. J Gynecol Surg 2016; 32: 73-8.

21. King NR, Lin E, Yeh C, et al. Laparoscopic major vascular injuries in gynecologic surgery for benign indications: a systematic review. Obstet Gynecol 2021; 137: 434-42. 
22. Llarena NC, Shah AB, Milad MP. Bowel injury in gynecologic laparoscopy: a systematic review. Obstet Gynecol 2015; 125: 1407-17.

23. Behbehani S, Suarez-Salvador E, Buras M, et al. Mortality rates in benign laparoscopic and robotic gynecologic surgery: a systematic review and meta-analysis. J Minim Invasive Gynecol 2020; 27: 603-12.e1.

24. Behbehani S, Suarez-Salvador E, Buras M, et al. Mortality rates in laparoscopic and robotic gynecologic oncology surgery: a systemic review and meta-analysis. J Minim Invasive Gynecol 2019; 26: 1253-67.e4.

25. Peterson HB, Greenspan JR, Ory HW. Death following punc ture of the aorta during laparoscopic sterilization. Obstet Gynecol 1982; 59: 133-4.

26. Vilos GA, Ternamian A, Vilos AG, et al. Direct laparoscopic trocar insertion: lessons learned from nine litigated cases. J Minim Invasive Gynecol 2017; 24: 960-70.

27. Fuller J, Ashar BS, Carey-Corrado J. Trocar-associated injuries and fatalities: an analysis of 1399 reports to the FDA. J Minim Invasive Gynecol 2005; 12: 302-7.

28. Gitas G, Alkatout I, Proppe L, et al. Surgical outcomes of conventional laparoscopic and robotic-assisted hysterectomy. Int J Med Robot 2021; 17: e2225.

29. Collins JA, Fauser BC. Balancing the strengths of systematic and narrative reviews. Hum Reprod Update 2005; 11: 103-4.

30. Baethge C, Goldbeck-Wood S, Mertens S. SANRA - a scale for the quality assessment of narrative review articles. Res Integr Peer Rev 2019; 4: 5.

31. National Cancer Institute. Common Terminology Criteria for Adverse Events (CTCAE). Feb 14 2021. Available at: https:// ctep.cancer.gov/protocoldevelopment/electronic_applications/ctc.htm\#ctc_50

32. Obermair A, Asher R, Pareja R, et al. Incidence of adverse events in minimally invasive vs open radical hysterectomy in early cervical cancer: results of a randomized controlled trial. Am J Obstet Gynecol 2020; 222: 249.e1-10.

33. Rodziewicz TL, Houseman B, Hipskind JE. Medical Error Reduc tion and Prevention. 2021. In: StatPearls [Internet]. Treasure Island (FL): StatPearls Publishing; 2021.

34. Rosenthal R, Hoffmann H, Dwan K, et al. Reporting of adverse events in surgical trials: critical appraisal of current practice. World J Surg 2015; 39: 80-7.

35. Clavien PA, Sanabria JR, Strasberg SM. Proposed classification of complications of surgery with examples of utility in cholecystectomy. Surgery 1992; 111: 518-26.

36. Dindo D, Demartines N, Clavien PA. Classification of surgical complications: a new proposal with evaluation in a cohort of $6336 \mathrm{pa}$ tients and results of a survey. Ann Surg 2004; 240: 205-13.

37. Sokol DK, Wilson J. What is a surgical complication? World J Surg 2008; 32: 942-4.

38. Meghelli L, Narducci F, Mariette C, et al. Reporting adverse events in cancer surgery randomized trials: a systematic review of published trials in oesophago-gastric and gynecological cancer patients. Crit Rev Oncol Hematol 2016; 104: 108-14.

39. Satava RM. Identification and reduction of surgical error using simulation. Minim Invasive Ther Allied Technol 2005; 14: 257-61.
40. Kazaryan AM, Røsok BI, Edwin B. Morbidity assessment in surgery: refinement proposal based on a concept of perioperative adverse events. ISRN Surg 2013; 2013: 625093.

41. Biyani CS, Pecanka J, Rouprêt M, et al. Intraoperative Adverse Incident Classification (EAUiaiC) by the European Association of Urology ad hoc Complications Guidelines Panel. Eur Urol 2020; 77: 601-10.

42. Strasberg SM, Linehan DC, Hawkins WG. The accordion severity grading system of surgical complications. Ann Surg 2009; 250: 177-86.

43. Bolliger M, Kroehnert JA, Molineus F, et al. Experiences with the standardized classification of surgical complications (Clavien-Dindo) in general surgery patients. Eur Surg 2018; 50: 256-61.

44. Radosa MP, Meyberg-Solomayer G, Radosa J, et al. Standardised registration of surgical complications in laparoscopic-gynaecological therapeutic procedures using the Clavien-Dindo classification. Geburtshilfe Frauenheilkd 2014; 74: 752-8.

45. Molinas CR, De Win G, Ritter O, et al. Feasibility and construct validity of a novel laparoscopic skills testing and training model. Gynecol Surg 2008; 5: 281-90.

46. Arbeitsgemeinschaft Gynäkologische Endoskopie. MIC-Qualifikation: erforderliche Fallzahlen/Eingriffstypen. Jan 11, 2021. Available at: https://www.ag-endoskopie.de/sites/age/files/ media/fallzahlen_und_eingriffstypen_1-2019_0.pdf

47. Alkatout I, Mettler L, Maass N, et al. Abdominal anatomy in the context of port placement and trocars. J Turk Ger Gynecol Assoc 2015; 16: 241-51.

48. Vilos GA, Ternamian A, Dempster J, et al. Laparoscopic entry: a review of techniques, technologies, and complications. J Obstet Gynaecol Can 2007; 29: 433-47.

49. Catarci M, Carlini M, Gentileschi P, et al. Major and minor injuries during the creation of pneumoperitoneum. A multicenter study on 12,919 cases. Surg Endosc 2001; 15: 566-9.

50. Pasic R, Levine RL, Wolf WM Jr. Laparoscopy in morbidly obese patients. J Am Assoc Gynecol Laparosc 1999; 6: 307-12.

51. Ahmad G, Baker J, Finnerty J, et al. Laparoscopic entry techniques. Cochrane Database Syst Rev 2019; 1: CD006583.

52. Cuss A, Bhatt $M$, Abbott J. Coming to terms with the fact that the evidence for laparoscopic entry is as good as it gets. J Minim Invasive Gynecol 2015; 22: 332-41.

53. Baggish MS. One hundred and thirty small-and-large-bowel injuries associated with gynecologic laparoscopic operations. J Gynecol Surg 2007; 23: 83-95.

54. Audebert AJ, Gomel V. Role of microlaparoscopy in the diagnosis of peritoneal and visceral adhesions and in the prevention of bowel injury associated with blind trocar insertion. Fertil Steril 2000; 73: 631-5.

55. Levrant SG, Bieber EJ, Barnes RB. Anterior abdominal wall adhesions after laparotomy or laparoscopy. J Am Assoc Gynecol Laparosc 1997; 4: 353-6.

56. Cheong YC, Premkumar G, Metwally M, et al. To close or not to close? A systematic review and a meta-analysis of peritoneal non-closure and adhesion formation after caesarean section. Eur J Obstet Gynecol Reprod Biol 2009; 147: 3-8.

57. Shi Z, Ma L, Yang Y, et al. Adhesion formation after previous caesarean section-a meta-analysis and systematic review. BJOG 2011; 118: 410-22. 
58. Teoh B, Sen R, Abbott J. An evaluation of four tests used to ascertain Veres needle placement at closed laparoscopy. J Minim Invasive Gynecol 2005; 12: 153-8.

59. Shawki O, Ramadan A, Askalany A, et al. Laparoscopic management of ovarian dermoid cysts: potential fear of dermoid spill, myths and facts. Gynecol Surg 2007; 4: 255-60.

60. Hizkiyahu R, Yahav L, Yakovi S, et al. Short- and long-term outcomes of intraoperative spillage during laparoscopic removal of benign ovarian cysts. Surg Endosc 2020; 34: 3883-7.

61. Panici PB, Palaia I, Bellati F, et al. Laparoscopy compared with laparoscopically guided minilaparotomy for large adnexal masses: a randomized controlled trial. Obstet Gynecol 2007; 110: 241-8.

62. Eisenberg N, Volodarsky-Perel A, Brochu I, et al. Short- and long-term complications of intraoperative benign ovarian cyst spillage: a systematic review and meta-analysis. J Minim Invasive Gynecol 2021; 28: 957-70.

63. Hursitoglu BS, Demirtas GS, Demirtas O, et al. A clinico-pathological evaluation of 194 patients with ovarian teratoma: 7-year experience in a single center. Ginekol Pol 2013; 84: 108-11.

64. Matsuo K, Huang Y, Matsuzaki S, et al. Minimally invasive surgery and risk of capsule rupture for women with early-stage ovarian cancer. JAMA Oncol 2020; 6: 1110-3.

65. Matsuo K, Machida H, Yamagami W, et al. Intraoperative capsule rupture, postoperative chemotherapy, and survival of women with stage I epithelial ovarian cancer. Obstet Gynecol 2019; 134: 1017-26.

66. Bogani G, Borghi C, Leone Roberti Maggiore U, et al. Minimally invasive surgical staging in early-stage ovarian carcinoma: a systematic review and meta-analysis. J Minim Invasive Gynecol 2017; 24: 552-62.

67. Kong Q, Wei H, Zhang J, et al. Comparison of the survival outcomes of laparoscopy versus laparotomy in treatment of early-stage ovarian cancer: a systematic review and meta-analysis. J Ovarian Res 2021; 14: 45.

68. Bogani G, Cromi A, Serati M, et al. Laparoscopic and open abdominal staging for early-stage ovarian cancer: our experience, systematic review, and meta-analysis of comparative studies. Int J Gynecol Cancer 2014; 24: 1241-9.

69. Jochum F, Vermel M, Faller E, et al. Three and five-year mortality in ovarian cancer after minimally invasive compared to open surgery: a systematic review and meta-analysis. J Clin Med 2020; 9: 2507.

70. Watrowski R, Zeillinger R. Simple laboratory score improves the preoperative diagnosis of adnexal mass. Tumour Biol 2016; 37: 4343-9.

71. Timmerman D, Planchamp F, Bourne T, et al. ESGO/ISUOG/ IOTA/ESGE Consensus Statement on preoperative diagnosis of ovarian tumours. Facts Views Vis Obgyn 2021; 13. doi: 10.52054/FVVO.13.2.016.

72. Bewö K, Österberg J, Löfgren M, et al. Incisional hernias following open gynecological surgery: a population-based study. Arch Gynecol Obstet 2019; 299: 1313-9.

73. Schiavone MB, Bielen MS, Gardner GJ, et al. Herniation formation in women undergoing robotically assisted laparoscopy or laparotomy for endometrial cancer. Gynecol Oncol 2016; 140: 383-6.
74. Gutierrez M, Stuparich M, Behbehani S, et al. Does closure of fascia, type, and location of trocar influence occurrence of port site hernias? A literature review. Surg Endosc 2020; 34: 5250-8.

75. Montz FJ, Holschneider CH, Munro MG. Incisional hernia following laparoscopy: a survey of the American Association of Gynecologic Laparoscopists. Obstet Gynecol 1994; 84: 881-4.

76. Cho WT, Yoo T, Kim SM. Is the 8-mm robotic port safe? A case of trocar site hernia after robotic cholecystectomy using the da Vinci Xi system. Videosurgery Miniinv 2019; 14: 137-40.

77. Micelli E, Russo E, Mannella P, et al. Severe bowel incarceration in an eight-millimeter left-lateral trocar site after robot-assisted laparoscopic colposacropexy: a case report. Case Rep Womens Health 2019; 24: e00151.

78. Pereira N, Chung ER, Irani M, et al. Incarcerated omental hernia at a $5-\mathrm{mm}$ trocar site after laparoscopy. J Minim Invasive Gynecol 2021; 28: 384-5.

79. Pereira N, Hutchinson AP, Irani M, et al. 5-millimeter trocar-site hernias after laparoscopy requiring surgical repair. J Minim Invasive Gynecol 2016; 23: 505-11.

80. Swank HA, Mulder IM, la Chapelle CF, et al. Systematic review of trocar-site hernia. Br J Surg 2012; 99: 315-23.

81. Haueter R, Schütz T, Raptis DA, et al. Meta-analysis of single-port versus conventional laparoscopic cholecystectomy comparing body image and cosmesis. Br J Surg 2017; 104: 1141-59.

82. Connell MB, Selvam R, Patel SV. Incidence of incisional hernias following single-incision versus traditional laparoscopic surgery: a meta-analysis. Hernia 2019; 23: 91-100.

83. Wells A, Germanos GJ, Salemi JL, et al. Laparoscopic surgeons' perspectives on risk factors for and prophylaxis of trocar site hernias: a multispecialty national survey. JSLS 2019; 23: e2019.00013.

84. Singal R, Zaman M, Mittal A, et al. No need of fascia closure to reduce trocar site hernia rate in laparoscopic surgery: a prospective study of 200 non-obese patients. Gastroenterology Res 2016; 9: 70-3.

85. Katara AN, Bhandarkar DS, Shah RS, et al. Breakage of fascial closure device during laparoscopic surgery. J Minim Access Surg 2005; 1: 79-81.

86. Lee $\mathrm{G}$, Nguyen A, Kivnick S, et al. Aortic puncture with a laparoscopic fascial closure device. Obstet Gynecol 2007; 110: 533-5.

87. Zivanovic O, Sonoda Y, Diaz JP, et al. The rate of port-site metastases after 2251 laparoscopic procedures in women with underlying malignant disease. Gynecol Oncol 2008; 111: 431-7.

88. Ramirez PT, Wolf JK, Levenback C. Laparoscopic port-site metastases: etiology and prevention. Gynecol Oncol 2003; 91: 179-89.

89. Lönnerfors C, Bossmar T, Persson J. Port-site metastases following robot-assisted laparoscopic surgery for gynecological malignancies. Acta Obstet Gynecol Scand 2013; 92: 1361-8.

90. Rindos N, Curry CL, Tabbarah R, et al. Port-site metastases after robotic surgery for gynecologic malignancy. JSLS 2014; 18: 66-70.

91. lavazzo C, Gkegkes ID. Port-site metastases in patients with gynecological cancer after robot-assisted operations. Arch Gynecol Obstet 2015; 292: 263-9.

92. Oindi FM, Mutiso SK, Obura T. Port site parasitic leiomyoma after laparoscopic myomectomy: a case report and review of the literature. J Med Case Rep 2018; 12: 339. 
93. Kai K, Aoyagi $Y$, Nishida $M$, et al. Port-site implantation of parasitic leiomyoma after laparoscopic myomectomy and its histopathology. SAGE Open Med Case Rep 2020; 8: $2050313 \times 20959223$.

94. Ma Z, Zhao L, Xu N, et al. Secondary pregnancy by an implant in a laparoscopic trocar site: a case report. Medicine 2018; 97: e0534.

95. Ramirez PT, Frumovitz M, Wolf JK, et al. Laparoscopic port-site metastases in patients with gynecological malignancies. Int J Gynecol Cancer 2004; 14: 1070-7.

96. Ataseven B, Grimm C, Harter P, et al. Prognostic impact of port-site metastasis after diagnostic laparoscopy for epithelial ovarian cancer. Ann Surg Oncol 2016; 23 (Suppl 5): 834-40.

97. Lago V, Gimenez L, Matute L, et al. Port site resection after laparoscopy in advance ovarian cancer surgery: time to abandon? Surg Oncol 2019; 29: 1-6.

98. Ataseven B, du Bois A, Harter P, et al. Impact of abdominal wall metastases on prognosis in epithelial ovarian cancer. Int J Gynecol Cancer 2016; 26: 1594-600.

99. Nunez MF, Sardi A, Jimenez W, et al. Port-site metastases is an independent prognostic factor in patients with peritoneal carcinomatosis. Ann Surg Oncol 2015; 22: 1267-73.

100. Schneider C, Jung A, Reymond MA, et al. Efficacy of surgical measures in preventing port-site recurrences in a porcine model. Surg Endosc 2001; 15: 121-5.

101. Hur HC, Guido RS, Mansuria SM, et al. Incidence and patient characteristics of vaginal cuff dehiscence after different modes of hysterectomies. J Minim Invasive Gynecol 2007; 14: 311-7.

102. Kho RM, AkI MN, Cornella J, et al. Incidence and characteristics of patients with vaginal cuff dehiscence after robotic procedures. Obstet Gynecol 2009; 114: 231-5.

103. Ceccaroni M, Berretta R, Malzoni M, et al. Vaginal cuff dehiscence after hysterectomy: a multicenter retrospective study. Eur J Obstet Gynecol Reprod Biol 2011; 158: 308-13.

104. Hur HC, Donnellan N, Mansuria S, et al. Vaginal cuff dehiscence after different modes of hysterectomy. Obstet Gynecol 2011; 118: 794-801.

105. Ala-Nissilä S, Laurikainen E, Mäkinen J, et al. Vaginal cuff dehiscence is observed in a higher rate after total laparoscopic hysterectomy compared with other types of hysterectomy. Acta Obstet Gynecol Scand 2019; 98: 44-50.

106. Uccella S, Malzoni M, Cromi A, et al. Laparoscopic vs transvaginal cuff closure after total laparoscopic hysterectomy: a randomized trial by the Italian Society of Gynecologic Endoscopy. Am J Obstet Gynecol 2018; 218: 500.e1-13.

107. Kashani S, Gallo T, Sargent A, et al. Vaginal cuff dehiscence in robotic-assisted total hysterectomy. JSLS 2012; 16: 530-6.

108. Uccella S, Zorzato PC, Kho RM. Incidence and prevention of vaginal cuff dehiscence after laparoscopic and robotic hysterectomy: a systematic review and meta-analysis. J Minim Invasive Gynecol 2021; 28: 710-20.

109. Drudi L, Press JZ, Lau S, et al. Vaginal vault dehiscence after robotic hysterectomy for gynecologic cancers: search for risk factors and literature review. Int J Gynecol Cancer 2013; 23: 943-50.

110. Albuquerque K, Shah K, Potkul R. Vaginal cuff dehiscence after intracavitary brachytherapy for endometrial cancer. J Contemp Brachytherapy 2012; 4: 111-2.
111. Lawlor ML, Rao R, Manahan KJ, et al. Electrosurgical settings and vaginal cuff complications. JSLS 2015; 19: e2015.00088.

112. Fuchs Weizman N, Einarsson Jl, Wang KC, et al. Vaginal cuff dehiscence: risk factors and associated morbidities. JSLS 2015; 19: e2013.00351.

113. Boersen Z, Aalders CIM, Klinkert ER, et al. Vaginal cuff dehiscence after endometriosis surgery. JSLS 2019; 23. pii: e2019.00018. doi: 10.4293/JSLS.2019.00018

114. Yildirim D, Ozyurek SE, Kiyak H, et al. Single-layer versus double-layer closure of the vaginal cuff with barbed sutures in laparoscopic hysterectomy. Ginekol Pol 2018; 89: 229-34.

115. López CC, Ríos JFL, González Y, et al. Barbed suture versus conventional suture for vaginal cuff closure in total laparoscopic hysterectomy: randomized controlled clinical trial. J Minim Invasive Gynecol 2019; 26: 1104-9.

116. Makin JC, Toscano M, Anderson EK, et al. Complications of robotic vaginal cuff closure with barbed versus non-barbed suture. Gynecol Oncol 2015; 137S1: 200.

117. McAllister JD, D’Altorio RA, Snyder A. CT findings after uncomplicated percutaneous laparoscopic cholecystectomy. J Comput Assist Tomogr 1991; 15: 770-2.

118. Murdock CM, Wolff AJ, Van Geem T. Risk factors for hypercarbia, subcutaneous emphysema, pneumothorax, and pneumomediastinum during laparoscopy. Obstet Gynecol 2000; 95: 704-9.

119. Kim CS, Kim JY, Kwon JY, et al. Venous air embolism during total laparoscopic hysterectomy: comparison to total abdominal hysterectomy. Anesthesiology 2009; 111: 50-4.

120. Lee DH, Song T, Kim KH, et al. Incidence, natural course, and characteristics of postlaparoscopic shoulder pain. Surg Endosc 2018; 32: 160-5.

121. Kietpeerakool C, Rattanakanokchai S, Yantapant A, et al. Pulmonary recruitment maneuver for reducing shoulder pain after laparoscopic gynecologic surgery: a network meta-analysis of randomized controlled trials. Minim Invasive Surg 2020; 2020: 7154612

122. Kaloo P, Armstrong S, Kaloo C, et al. Interventions to reduce shoulder pain following gynaecological laparoscopic procedures. Cochrane Database Syst Rev 2019; 1: CD011101.

123. Kiyak H, Yilmaz G, Ay N. Semi-Fowler positioning in addition to the pulmonary recruitment manoeuvre reduces shoulder pain following gynaecologic laparoscopic surgery. Videosurgery Miniinv 2019; 14: 567-74.

124. Ryu KH, Lee SH, Cho EA, et al. Comparison of impacts of intraperitoneal saline instillation with and without pulmonary recruitment maneuver on post-laparoscopic shoulder pain prevention: a randomized controlled trial. Surg Endosc 2019; 33: $870-8$.

125. Yilmaz G, Kiyak H, Akca A, et al. Low-pressure pulmonary recruitment maneuver: equal to or worse than moderate-pressure pulmonary recruitment maneuver in preventing postlaparoscopic shoulder pain? A randomized controlled trial of 72 patients. Videosurgery Miniinv 2020; 15: 519-25.

126. Driessen SR, Arkenbout EA, Thurkow AL, et al. Electromechanical morcellators in minimally invasive gynecologic surgery: an update. J Minim Invasive Gynecol 2014; 21: 377-83.

127. Brölmann H, Tanos V, Grimbizis G, et al. Options on fibroid morcellation: a literature review. Gynecol Surg 2015; 12: 3-15. 
128. Tulandi T, Leung A, Jan N. Nonmalignant sequelae of unconfined morcellation at laparoscopic hysterectomy or myomectomy. J Minim Invasive Gynecol 2016; 23: 331-7.

129. Milad MP, Milad EA. Laparoscopic morcellator-related complications. J Minim Invasive Gynecol 2014; 21: 486-91.

130. Darii N, Anton E, Doroftei B, et al. latrogenic parasitic myoma and iatrogenic adenomyoma after laparoscopic morcellation: a mini-review. J Adv Res 2019; 20: 1-8.

131. Theben JU, Schellong AR, Altgassen C, et al. Unexpected malignancies after laparoscopic-assisted supracervical hysterectomies (LASH): an analysis of 1,584 LASH cases. Arch Gynecol Obstet 2013; 287: 455-62.

132. Wright JD, Tergas Al, Cui R, et al. Use of electric power morcellation and prevalence of underlying cancer in women who undergo myomectomy. JAMA Oncol 2015; 1: 69-77.

133. Pritts EA, Vanness DJ, Berek JS, et al. The prevalence of occult leiomyosarcoma at surgery for presumed uterine fibroids: a meta-analysis. Gynecol Surg 2015; 12: 165-77.

134. Bogani G, Cliby WA, Aletti GD. Impact of morcellation on survival outcomes of patients with unexpected uterine leiomyosarcoma: a systematic review and meta-analysis. Gyneco Oncol 2015; 137: 167-72.

135. Raspagliesi F, Maltese G, Bogani G, et al. Morcellation wors ens survival outcomes in patients with undiagnosed uterine leiomyosarcomas: a retrospective MITO group study. Gynecol Oncol 2017; 144: 90-5.

136. Xu X, Lin H, Wright JD, et al. Association between power morcellation and mortality in women with unexpected uterine cancer undergoing hysterectomy or myomectomy. J Clin Oncol 2019; 37: 3412-24.

137. Odejinmi F, Aref-Adib M, Liou N, et al. Rethinking the issue of power morcellation of uterine fibroids: is morcellation the real problem or is this another symptom of disparity in healthcare provision? In Vivo 2019; 33: 1393-401.

138. Goto A, Takeuchi S, Sugimura K, et al. Usefulness of Gd-DTPA contrast-enhanced dynamic MRI and serum determination of LDH and its isozymes in the differential diagnosis of leiomyosarcoma from degenerated leiomyoma of the uterus. Int J Gynecol Cancer 2002; 12: 354-61.

139. Bansal N, Herzog TJ, Burke W, et al. The utility of preoperative endometrial sampling for the detection of uterine sarcomas. Gynecol Oncol 2008; 110: 43-8.

140. Zaami S, Zupi E, Lazzeri L, et al. Medicolegal issues in power morcellation: cautionary rules for gynecologists to avoid unfavorable outcomes. J Minim Invasive Gynecol 2020; 27 583-92.

141. U.S. Department of Health and Human Services Food and Drug Administration. Product Labeling for Laparoscopic Power Morcellators. Guidance for Industry and Food and Drug Administration Staff. Dec 29, 2020. Available at: https://www. fda.gov/media/90012/download

142. Meurs EAIM, Brito LG, Ajao MO, et al. Comparison of morcellation techniques at the time of laparoscopic hysterectomy and myomectomy. J Minim Invasive Gynecol 2017; 24: 843-9.

143. Cohen SL, Morris SN, Brown DN, et al. Contained tissue extraction using power morcellation: prospective evaluation of leakage parameters. Am J Obstet Gynecol 2016; 214: 257.e1-6.
144. Hong MK, Wei YC, Chu TY, et al. Safety and efficacy of contained manual morcellation during laparoscopic or robotic gynecological surgery. Int J Gynaecol Obstet 2020; 148: 168-73.

145. Zullo F, Venturella R, Raffone A, et al. In-bag manual versus uncontained power morcellation for laparoscopic myomectomy. Cochrane Database Syst Rev 2020; 5: CD013352.

146. Alkatout I, Schollmeyer T, Hawaldar NA, et al. Principles and safety measures of electrosurgery in laparoscopy. JSLS 2012; 16: 130-9.

147. Seehofer D, Mogl M, Boas-Knoop S, et al. Safety and efficacy of new integrated bipolar and ultrasonic scissors compared to conventional laparoscopic 5-mm sealing and cutting instruments. Surg Endosc 2012; 26: 2541-9.

148. Hefermehl LJ, Largo RA, Hermanns T, et al. Lateral temperature spread of monopolar, bipolar and ultrasonic instruments for robot-assisted laparoscopic surgery. BJU Int 2014; 114: 245-52.

149. van der Voort M, Heijnsdijk EA, Gouma DJ. Bowel injury as a complication of laparoscopy. Br J Surg 2004; 91: 1253-8.

150. Baggish MS. Urinary tract injuries secondary to gynecologic laparoscopic surgery: analysis of seventy-five cases. J Gynecol Surg 2010; 26: 79-92.

151. Gualniera P, Scurria S, Sapienza D, et al. Electrosurgical unit: latrogenic injuries and medico-legal aspect. Italian legal rules, experience and article review. Ann Med Surg 2021; 62: 26-30.

152. Paracchini S, Bustos B, Aviles R, et al. Equipment failures in laparoscopic surgery: Causes and consequences. J Visc Surg 2020: S1878-7886(20)30275-7. doi: 10.1016/j.jviscsurg.2020.10.018.

153. Watanabe Y, Kurashima Y, Madani A, et al. Surgeons have knowledge gaps in the safe use of energy devices: a multicenter cross-sectional study. Surg Endosc 2016; 30: 588-92.

154. Montero PN, Robinson TN, Weaver JS, et al. Insulation failure in laparoscopic instruments. Surg Endosc 2010; 24: 462-5.

155. Saaiq M, Zaib S, Ahmad S. Electrocautery burns: experience with three cases and review of literature. Ann Burns Fire Disasters 2012; 25: 203-6.

156. Sultan SA, Alahmadi B, Mohabbat A Sr. Hand skin burn as a complication of electrosurgery use in prone position in surgery: a case report. Cureus 2020; 12: e10101.

157. Willson PD, van der Walt JD, Moxon D, et al. Port site electrosurgical (diathermy) burns during surgical laparoscopy. Surg Endosc 1997; 11: 653-4.

158. Isager P, Lind T. Accidental third-degree burn caused by bipolar electrocoagulation. Injury 1995; 26: 357.

159. Hindle AK, Brody F, Hopkins V, et al. Thermal injury secondary to laparoscopic fiber-optic cables. Surg Endosc 2009; 23: 1720-3.

160. Courdier S, Garbin O, Hummel M, et al. Equipment failure: causes and consequences in endoscopic gynecologic surgery. J Minim Invasive Gynecol 2009; 16: 28-33.

161. Yazdani A, Krause H. Laparoscopic instrument insulation failure: the hidden hazard. J Minim Invasive Gynecol 2007; 14: 228-32.

162. Tixier F, Garçon M, Rochefort F, et al. Insulation failure in electrosurgery instrumentation: a prospective evaluation. Surg Endosc 2016; 30: 4995-5001.

163. Feldman LS, Fuchshuber P, Jones DB, et al. Surgeons don't know what they don't know about the safe use of energy in surgery. Surg Endosc 2012; 26: 2735-9. 
164. Alemzadeh H, Raman J, Leveson N, et al. Adverse events in robotic surgery: a retrospective study of 14 years of FDA data. PLoS One 2016; 11: e0151470.

165. Rajih E, Tholomier C, Cormier B, et al. Error reporting from the da Vinci surgical system in robotic surgery: a Canadian multispecialty experience at a single academic centre. Can Urol Assoc J 2017; 11: E197-202.

166. Medina LG, Martin O, Cacciamani GE, et al. Needle lost in minimally invasive surgery: management proposal and literature review. J Robot Surg 2018; 12: 391-5.

167. Kandioler-Eckersberger D, Niederle B, Herbst F, et al. A magnetic probe to retrieve broken metallic parts of instruments during laparoscopic procedures. Surg Endosc 2002; 16: 208-9.

168. Katara AN, Bhandarkar DS, Shah RS, et al. Breakage of fascial closure device during laparoscopic surgery. J Minim Access Surg 2005; 1: 79-81.

169. Sharma AP, Mete UK, Bendapuddi D, et al. Needle in a haystack: lost in transition. J Robot Surg 2018; 12: 177-9.

170. Jayadevan R, Stensland K, Small A, et al. A protocol to recover needles lost during minimally invasive surgery. JSLS 2014; 18: e2014.00165.

171. Wong C, Merkur H. Inferior epigastric artery: surface anatomy, prevention and management of injury. Aust N Z J Obstet Gynaecol 2016; 56: 137-41.

172. Asfour V, Smythe E, Attia R. Vascular injury at laparoscopy: a guide to management. J Obstet Gynaecol 2018; 38: 598-606.

173. Deffieux X, Ballester M, Collinet P, et al. Risks associated with laparoscopic entry: guidelines for clinical practice from the French College of Gynaecologists and Obstetricians. Eur J Obstet Gynecol Reprod Biol 2011; 158: 159-66.

174. Paśnik B, Modrzejewski A. Major vascular injury during laparoscopy. Pol Przegl Chir 2018; 91: 36-40.

175. Chapron C, Pierre F, Harchaoui Y, et al. Gastrointestinal injuries during gynaecological laparoscopy. Hum Reprod 1999; 14: 333-7.

176. Picerno T, Sloan NL, Escobar P, et al. Bowel injury in robotic gynecologic surgery: risk factors and management options. A systematic review. Am J Obstet Gynecol 2017; 216: 10-26.

177. Warner WB, Vora S, Alonge A, et al. Intraoperative and postoperative gastrointestinal complications associated with laparoscopic sacrocolpopexy. Female Pelvic Med Reconstr Surg 2012; 18: 321-4.

178. Teeluckdharry B, Gilmour D, Flowerdew G. Urinary tract injury at benign gynecologic surgery and the role of cystoscopy: a systematic review and meta-analysis. Obstet Gynecol 2015; 126: 1161-9.

179. Burks FN, Santucci RA. Management of iatrogenic ureteral injury. Ther Adv Urol 2014; 6: 115-24.

180. Kapogiannis F, Spartalis E, Fasoulakis K, et al. Laparoscopic and robotic management of ureteral stricture in adults. In Vivo 2020; 34: 965-72.

181. Adelman MR, Bardsley TR, Sharp HT. Urinary tract injuries in laparoscopic hysterectomy: a systematic review. J Minim Invasive Gynecol 2014; 21: 558-66.

182. Wong JMK, Bortoletto P, Tolentino J, et al. Urinary tract injury in gynecologic laparoscopy for benign indication: a systematic review. Obstet Gynecol 2018; 131: 100-8.
183. Hwang JH, Kim BW. Laparoscopic radical hysterectomy has higher risk of perioperative urologic complication than $a b$ dominal radical hysterectomy: a meta-analysis of 38 studies. Surg Endosc 2020; 34: 1509-21.

184. Watrowski R, Babbel B, Fisch D. Renal calyceal rupture following ureteral injury after total laparoscopic hysterectomy. Gynecol Minim Invasive Ther 2020; 9: 166-9.

185. Abdalmageed OS, Bedaiwy MA, Falcone T. Nerve injuries in gynecologic laparoscopy. J Minim Invasive Gynecol 2017; 24: 16-27.

186. Kuponiyi O, Alleemudder DI, Latunde-Dada A, et al. Nerve injuries associated with gynaecological surgery. Obstet Gynaecol 2014; 16: 29-36.

187. Maerz DA, Beck LN, Sim AJ, et al. Complications of robotic-assisted laparoscopic surgery distant from the surgical site. $\mathrm{Br}$ J Anaesth 2017; 118: 492-503.

188. Bradshaw AD, Advincula AP. Postoperative neuropathy in gynecologic surgery. Obstet Gynecol Clin North Am 2010; 37 : 451-9.

189. Bjøro B, Mykkeltveit I, Rustøen T, et al. Intraoperative peripheral nerve injury related to lithotomy positioning with steep Trendelenburg in patients undergoing robotic-assisted laparoscopic surgery - a systematic review. J Adv Nurs 2020; 76 : 490-503.

190. Shin JH, Howard FM. Abdominal wall nerve injury during laparoscopic gynecologic surgery: incidence, risk factors, and treatment outcomes. J Minim Invasive Gynecol 2012; 19: 448-53.

191. Philosophe R. Avoiding complications of laparoscopic surgery. Fertil Steril 2003; 80 Suppl 4: 30-9.

192. Warner MA, Martin JT, Schroeder DR, et al. Lower-extremity motor neuropathy associated with surgery performed on patients in a lithotomy position. Anesthesiology 1994; 81: 6-12.

193. Whitis AM, Chen E, Sekhon M, et al. Postoperative lower extremity neuropathy with boot stirrups compared with candy cane stirrups. Obstet Gynecol 2021; 137: 916-23.

194. Kostov S, Kornovski Y, Slavchev S, et al. Pelvic lymphadenectomy in gynecologic oncology-significance of anatomical variations. Diagnostics 2021; 11: 89.

195. O'Hanlan KA, Emeney PL, Peters A, et al. Analysis of a standardized technique for laparoscopic cuff closure following 1924 total laparoscopic hysterectomies. Minim Invasive Surg 2016; 2016: 1372685.

196. van den Haak L, Alleblas C, Nieboer TE, et al. Efficacy and safety of uterine manipulators in laparoscopic surgery: a review. Arch Gynecol Obstet 2015; 292: 1003-11.

197. Gupta N, Depasquale S. Robotic repair of incidental vaginal laceration during da Vinci-assisted TLH. J Minim Invasive Gynecol 2017; 24: S185.

198. Walters Haygood CL, Fauci JM, Huddleston-Colburn MK, et al. Outcomes of gynecologic oncology patients undergoing robotic-assisted laparoscopic procedures in a university setting. J Robot Surg 2014; 8: 207-11.

199. Ng CC, Chern BS. Total laparoscopic hysterectomy: a 5-year experience. Arch Gynecol Obstet 2007; 276: 613-8.

200. Jena AB, Seabury S, Lakdawalla D, et al. Malpractice risk according to physician specialty. N Engl J Med 2011; 365 : 629-36. 
201. Glaser LM, Alvi FA, Milad MP. Trends in malpractice claims for obstetric and gynecologic procedures, 2005 through 2014. Am J Obstet Gynecol 2017; 217: 340.e1-6.

202. Sandberg EM, Bordewijk EM, Klemann D, et al. Medical malpractice claims in laparoscopic gynecologic surgery: a Dutch overview of 20 years. Surg Endosc 2017; 31: 5418-26.

203. Corson SL, Chandler JG, Way LW. Survey of laparoscopic entry injuries provoking litigation. J Am Assoc Gynecol Laparosc 2001; 8: 341-7.

204. Varma R, Gupta JK. Laparoscopic entry techniques: clinical guideline, national survey, and medicolegal ramifications. Surg Endosc 2008; 22: 2686-97.

205. Gawande AA, Thomas EJ, Zinner MJ, et al. The incidence and nature of surgical adverse events in Colorado and Utah in 1992. Surgery 1999; $126: 66-75$.

206. Wedel T, Ackermann J, Hagedorn H, et al. Educational training in laparoscopic gynecological surgery based on ethanol-glycerol-lysoformin-preserved body donors. Ann Anat 2019; 221: 157-64.

207. Alkatout I, Dhanawat J, Ackermann J, et al. Video feedback and video modeling in teaching laparoscopic surgery: a visionary concept from Kiel. J Clin Med 2021; 10: 163.

Received: 20.03.2021, accepted: 30.06 .2021 